\title{
LA FACTORÍA DE BAHÍA THETIS, ANTECEDENTES HISTÓRICOS Y TAFONOMÍA DE CAMADAS DE HUESOS DE PINNÍPEDOS
}

\author{
MARTÍN VÁZQUEZa ${ }^{a}$ FERNANDO SANTIAGOa \& \\ ATILIO FRANCISCO ZANGRANDO
}

\begin{abstract}
RESUMEN
Las costas de Península Mitre, en el extremo oriental de la Isla Grande de Tierra del Fuego, albergan gran cantidad de apostaderos de pinnípedos que fueron objeto de la explotación intensiva por parte de loberos europeos, estadounidenses y criollos desde el siglo XVIII. En la década de 1940 en bahía Thetis funcionó una factoría dedicada a la obtención de cueros y aceite de estos animales, de la cual aún se conservan restos de algunas de sus instalaciones y grandes acumulaciones de huesos de los animales faenados. En este artículo se ofrecen datos históricos sobre la explotación de pinnípedos en la región de Península Mitre y las modalidades de obtención y aprovechamiento a escala industrial de estas presas realizadas en la factoría de bahía Thetis. Asimismo, se presentan los análisis zooarqueológicos y tafonómicos de camadas de huesos (bonebeds) de pinnípedos emplazadas en un sector de esta bahía. Los resultados presentados nos permiten profundizar en algunas propuestas previas en las cuales se sostiene que estas camadas de huesos son producto de una acumulación secundaria, generada por la acción de las mareas, de restos descartados por la faena de animales en la factoría de lobos marinos que funcionó en esta bahía.
\end{abstract}

PALABRAS CLAVE: camadas de huesos, pinnípedos, explotación industrial, zooarqueología, Tierra del Fuego.

\section{THE THETIS BAY FACTORY, HISTORIC BACKGROUND AND TAPHONOMY OF PINNIPED BONEBEDS}

\begin{abstract}
Several Otarid rookeries are located along the coasts of the Peninsula Mitre, at the Eastern end of the Isla Grande de Tierra del Fuego, which were the subject of intensive exploitation by European, American and Criollo sealers since the $18^{\text {th }}$ century. In the 1940 s, a factory for extracting leather and oil from these animals was established in Thetis Bay. Remains of its facilities are still preserved, along


with large accumulations of bones from animals slaughtered there. This paper provides historical data on the exploitation of pinnipeds in Península Mitre and on the methods for obtaining and exploiting these marine mammals at an industrial scale. The paper likewise includes the zooarchaeological and taphonomic analyses of pinniped bonebeds located in a sector of Thetis Bay. The presented results allow us to delve into some previous proposals which argue that these bonebeds are the product of a secondary accumulation - generated by tidal action - of remains discarded after the animal slaughter at the factory.

KEY WORDS: bonebeds, pinnipeds, industrial exploitation, zooarchaeology, Tierra del Fuego.

\section{INTRODUCCIÓN}

Este artículo presenta el análisis de un sitio arqueológico formado por densas acumulaciones de huesos de pinnípedos, localizado en la bahía Thetis, Tierra del Fuego, Argentina. Previamente se propuso que estos depósitos de huesos eran producto de un proceso de acumulación secundaria, ocasionada por la acción de las mareas, de los restos de pinnípedos faenados durante el funcionamiento de una factoría durante la década de 1940 (Vázquez \& Santiago, 2014). Aquí nuestro objetivo es aportar nuevos datos y discutir con mayor profundidad los procesos vinculados a la formación de estas acumulaciones.

Con el fin de contextualizar la información ofrecida por los análisis zooarqueológicos y tafonómicos, en primer lugar se presenta una sintesis de la información histórica referida a la explotación de mamíferos marinos en el Atlántico sur, especialmente aquella concerniente a la explotación de pinnípedos realizada en las costas de Península Mitre durante el siglo XX, dentro de la cual la factoría emplazada en bahía Thetis era la de mayor actividad. En segundo lugar, se profundizan algunas observaciones de campo realizadas sobre las acumulaciones de huesos, caracterizando el emplazamiento de los depósitos y ofreciendo datos relativos a su densidad, abundancia taxonómica y anatómica. Por último, presentamos nueva información zooarqueológica y tafonómica a partir de la cual discutimos hipótesis planteadas previamente. De esta manera, buscamos ampliar y discutir algunos aspectos relacionados a los procesos y agentes vinculados a la formación del sitio y aportar, a partir de un caso particular, a la caracterización de este tipo de depósitos arqueológicos.

Los estudios tafonómicos orientados a la caracterización y comprensión de la variabilidad de procesos que actúan en ámbitos costeros tienen recientes y significativos aportes en el ámbito de Fuego-Patagonia ( Borella \& Favier Dubois, 199495; Borella, 2004; Borrero, 2004; Borella \& Muñoz, 2006; Borella \& Borrero, 2017, entre otros), aunque son aún muy escasos los casos registrados de acumulaciones masivas de huesos de mamíferos marinos (Serrán et al. 2008), pese a que el estudio de las denominadas "bonebeds" es un tópico abordado recurrentemente desde perspectivas arqueológicas y paleontológicas ( Frison \& Todd, 1987; Behrensmeyer, 1991, 2007; Rogers et al. 2007, entre otros). En el ámbito de la zooarqueología argentina, el concepto de bonebed ha sido utilizado de manera informal y generalmente ha sido traducido como "camada" o "cama de huesos", aplicado a densas acumulaciones de restos de vertebrados terrestres (Miotti et al. 1999; Gutiérrez, 2001; Santiago \& Salemme, 2010, 2016). En términos generales estas grandes acumulaciones de huesos implican una concentración de restos de vertebrados, relativamente densa, localizada en un área o unidad sedimentaria y donde se conservan restos de más de un individuo (Behrensmeyer, 1991, 2007; Eberth et al. 2007b). En términos más específicos han sido caracterizadas como concentraciones de huesos inusualmente densas, depositadas en un solo estrato sedimentario; a menudo, pero no necesariamente, los huesos representan al menos el 5\% del volumen del estrato (Behrensmeyer, 2007, p. 66). Generalmente corresponden a estratos "relativamente enriquecidos" con restos de vertebrados, cuya densidad de huesos es considerablemente mayor que la de los restantes estratos (Rogers \& Kidwell, 2007). También se ha propuesto que es una acumulación que consta de restos completos o parciales de más de un individuo en notable concentración en una capa horizontal o superficie erosiva (Eberth et al. 2007b, p, 106). Para los mencionados autores la noción básica 
para identificar un conjunto como bonebed es el carácter "notable" o "inusual" de la concentración, implicando en este rasgo la presencia de una muy alta densidad de elementos óseos que excede por mucho la ocurrencia normal de los huesos en la formación o lugar que los contiene.

Dadas las características mencionadas, estas grandes acumulaciones de huesos ofrecen, además de los aspectos zooarqueológicos y tafonómicos que conforman el foco de este trabajo, posibilidades de abordar aspectos tales como parámetros poblacionales o paleoecológicos cuyo estudio se ve limitado en conjuntos con menor cantidad de especímenes y donde la representación de cantidades de individuos y clases es mucho menor.

\section{MARCO HISTÓRICO SOBRE LA EXPLOTACIÓN DE PINNÍPEDOS EN TIERRA DEL FUEGO}

De manera análoga a la propuesta de Reeves (2002) para la explotación de cetáceos, se pueden distinguir dos etapas históricas en la explotación de lobos marinos por parte de los humanos en Tierra del Fuego, que a su vez implicaron dos escalas de explotación diferentes: una de subsistencia y otra comercial o industrial. En la primera etapa el objetivo de la caza de pinnípedos era el aprovechamiento local de los animales por distintas poblaciones cazadoras-recolectoras que habitaron la isla. En la segunda, el objetivo de las cacerías era comercializar los productos derivados de los lobos marinos en el mercado mundial.

Explotación de subsistencia de lobos marinos en Tierra del Fuego

Existe abundante evidencia arqueológica que da cuenta de las modalidades de explotación de pinnípedos en la Isla Grande de Tierra del Fuego, desde hace al menos 6.400 años AP. Esquemáticamente existieron dos estrategias básicas de explotación en esta región. Entre los cazadores-recolectores pedestres que habitaron el norte y centro de la Isla Grande, los pinnípedos fueron considerados como un recurso complementario (Borrero, 1985; Muñoz, 2002, 2011; Santiago, 2013). La relevancia de estos mamíferos marinos radicaba en el aporte de lípidos y grasas, extremadamente necesarios para suplementar la carne magra del principal recurso, el guanaco. En tanto para los cazadores-recolectorespescadores con tecnología de navegación, que habitaron la costa sur de Tierra del Fuego, los lobos marinos tuvieron un aporte mucho mayor a la subsistencia, por momentos preponderante (Schiavini, 1993; Orquera \& Piana, 1999; Zangrando et al. 2010; Martinoli, 2017; Martinoli \& Vázquez, 2017), aunque luego de los 5.000 años AP de la secuencia arqueológica del canal Beagle su consumo habría decrecido en relación con otros recursos (Zangrando, 2009). Hasta el momento, la información referida a la explotación de pinnípedos para el área de Península Mitre es limitada y está restringida a un par de localidades en la vertiente atlántica y solo una en la costa sur. Se ha propuesto una modalidad de estrategias de explotación generalizada y en tierra para la costa atlántica (Lanata \& Winograd, 1988; Muñoz, $2000,2002,2011)$ y la potencial coexistencia de estrategias de cacería tanto en tierra como en el agua para la costa sur (Martinoli, 2017).

\section{Explotación industrial de mamíferos marinos en el Atlántico sur}

Los inicios de la explotación industrial de pinnípedos en los mares del sur datan de fines del siglo XVIII. Motivadas por la creciente demanda de aceite producida por la revolución industrial en Europa y la sobreexplotación de cetáceos y pinnípedos llevada a cabo en el hemisferio norte, las cacerías volcaron su atención hacia el Atlántico sur (Stehberg \& Cabeza, 1987; Muñoz, 2000; Quiroz, 2007; Zarankin \& Senatore, 2007; Caviglia, 2012). Hacia principios del siglo XIX, las intensas cacerías realizadas por décadas en las costas patagónicas y fueguinas trajeron como consecuencia una drástica disminución del recurso, llevando a las poblaciones de pinnípedos al borde de su extinción. Esto impulsó a las expediciones a aventurarse cada vez más al sur en la búsqueda de loberías no explotadas, con la consecuente exploración de los mares antárticos. Aunque desde el siglo XVII ya se tenían noticias de la existencia de islas en latitudes tan australes como las Georgias y las Shetland del Sur (Piana, 2006), las explotaciones loberas y balleneras se establecieron 
en las islas Shetland y la península Antártica hacia inicios del siglo XIX (Muñoz, 2000; Senatore et al. 2008). El periodo de mayor actividad de loberos en los mares australes se registró entre 1819 y 1831 (Caviglia, 2012).

En tiempos más recientes y dentro del territorio continental argentino fueron varias las loberías explotadas en escala industrial. Entre las más destacadas se mencionan: Bahía del Fondo -al sur de Comodoro Rivadavia-, Punta Buenos Aires, Punta Norte y Punta Ninfa -en Península Valdés-, Monte León -al sur de Puerto Santa Cruz- y Punta Buque u Oso Marino -al sur de Puerto Deseado(Carrara, 1952, p. 125). Recién durante la primera mitad del siglo XX el gobierno argentino reglamentó esta actividad otorgando concesiones. Las cacerías y la explotación industrial de lobos marinos de un pelo (Otaria flavescens) fueron reglamentadas mediante el Decreto N 56.844 del 7 de marzo de 1940 (Carrara, 1952, p.145). Los registros consignados por Carrara indican que el año más productivo fue 1946. Si se considera la totalidad de explotaciones loberas registradas en Patagonia, se llegaron a faenar más de 31.000 animales, siendo las localizadas en Tierra del Fuego las más productivas (Carrara, 1952, p. 143; Bruno Videla, 1980; Winograd, 1984). Hacia fines de esta década las poblaciones de pinnípedos habían sido diezmadas en Tierra del Fuego, Patagonia y las islas Malvinas (Baylis et al. 2015) hasta que en 1949 fueron prohibidas las cacerías en todo el territorio nacional, mientras que en el territorio bajo control británico se prohíben recién en 1964 (Baylis et al. 2015).

\section{La explotación industrial de}

lobos marinos en Península Mitre

Hacia mediados de la década de 1940 habían sido otorgadas tres concesiones en Tierra del Fuego, todas ellas en las costas de Península Mitre. Según Carrara (1952, p. 125) los titulares y la extensión de estas concesiones eran las siguientes: Alcira R. de Sánchez Reynafé, desde caleta Policarpo a bahía Thetis, y Augusto O. Huber, desde Punta Este sin nombre -de bahía Thetis- a bahía Buen Suceso (Fig. 1). Estas dos concesiones eran las que estaban relacionadas al ámbito geográfico de la factoría de bahía Thetis. Para la costa sureste de la Península, también menciona la concesión de Ludovico Haberkorn, desde cabo Buen Suceso hasta cabo San Pío. A su vez, Zanola (2002) señala que en 1940 Sánchez Reynafé y Huber establecieron una compañía denominada "Sociedad Argentina de Industrialización, Comercio, Caza y Pesca Sociedad Anónima" (SADICCAP), la cual se dedicó al faenamiento de lobos marinos. A partir de esta información se puede suponer que ambas concesiones, fusionadas en una misma sociedad, utilizaban la factoría de bahía Thetis para sus actividades. Lamentablemente hasta el momento no hemos tenido acceso a registros más precisos y desconocemos detalles acerca del funcionamiento de estas concesiones.

A partir de los censos realizados entre 1946 y 1949 (Carrara, 1952), época en la cual la factoría de Thetis estaba en funcionamiento, tenemos conocimiento de la existencia de al menos ocho apostaderos de pinnípedos en el área de influencia de estas dos concesiones. Las ubicaciones de estas loberías pueden apreciarse en la Fig. 1 y sus denominaciones, de este a oeste, son: Falsa Caleta Policarpo (actualmente denominada Caleta Centenario), Las Piedras, Las Chapas, Caleta Tres Amigos, Cabo San Vicente, La Laguna, Caleta Ferrio y Cabo San Diego. Para un relevamiento más reciente ver también el trabajo de Schiavini y Raya Rey (2001).

\section{CASO DE ESTUDIO: LA FACTORÍA DE BAHÍA THETIS}

Este establecimiento funcionó entre 1940 y 1948, concentrando las actividades entre la primavera y el otoño, periodos en los cuales se llegaron a albergar hasta 200 personas en sus instalaciones (Zanola, 2002; Winograd, 2008). Cerca del $95 \%$ de los trabajadores dedicados a la caza, faena y procesamiento de los productos animales era de origen chileno (Carrara, 1952). Según este último autor, de todas las concesiones otorgadas en territorio argentino, una de las que más se destacaba por la calidad y el estado de sus instalaciones era la factoría de bahía Thetis.

La obtención de las presas se realizaba normalmente mediante una estrategia de encierro en los apostaderos, en los cuales -preferentemente durante la bajamar- la 


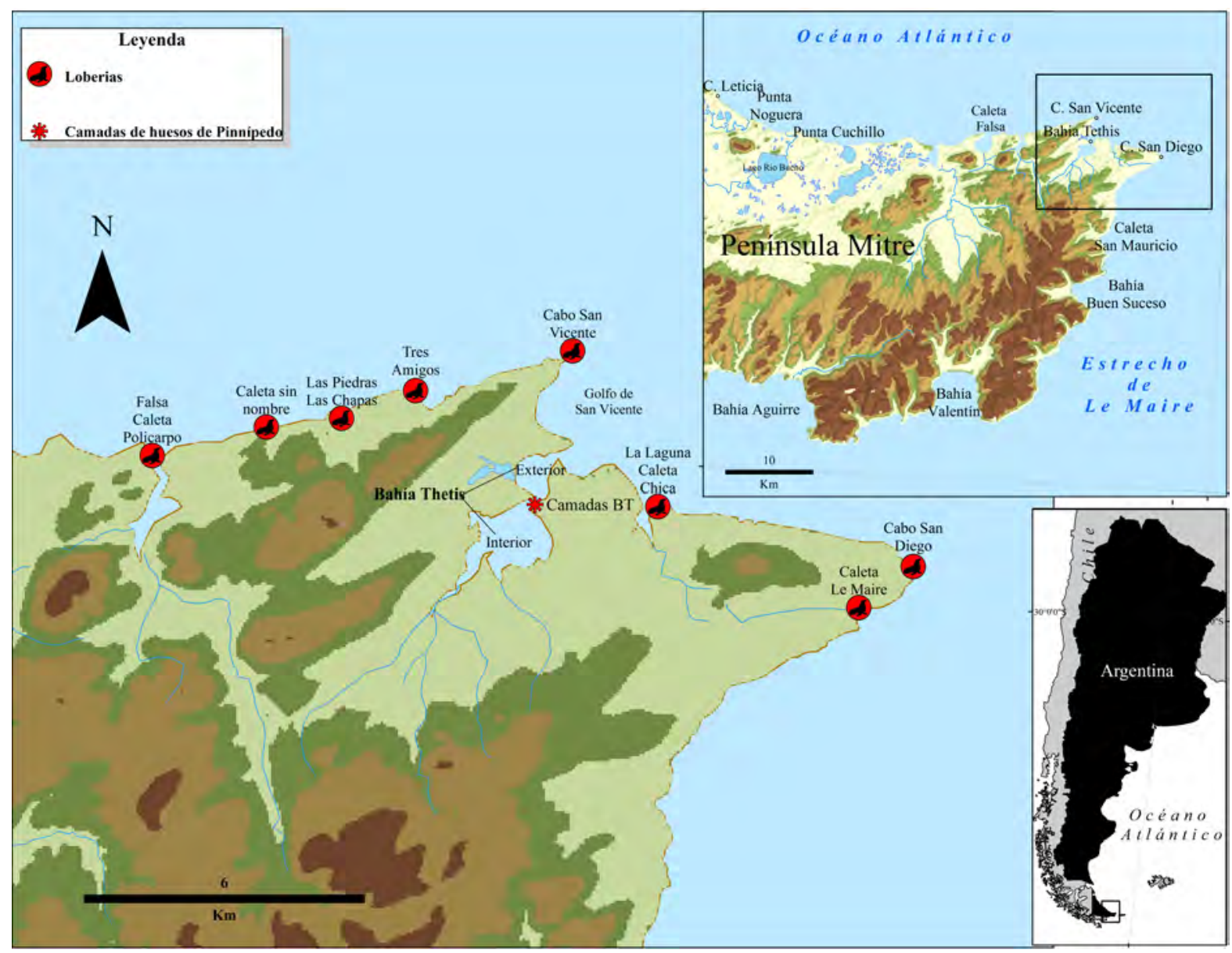

Fig. 1. Mapa de ubicación: principales localidades mencionadas en el texto y posición de las loberías consignadas por Carrara (1952).

"comparsa"1 de loberos encerraba grupos de animales interponiéndose entre la costa y los espacios de descanso, impidiéndoles la posibilidad de huir. Una vez separado un "piño"2 de la manada original, este era arreado hasta los lugares donde se efectuaba la matanza. Alejados del agua y sin posibilidades de escapar, los animales eran reducidos mediante golpes en la cabeza, dejándolos inconscientes o aturdidos y se los ultimaba con un "pico de albañil" asestándole un golpe letal con su parte punzante en la región parietal (Carrara, 1952) (Fig. 2). Normalmente este procedimiento implicaba la participación de dos personas, la primera portando un "trozo de

1 Grupo de trabajadores, loberos, que integraban los equipos o cuadrillas dedicadas a las tareas de cacería y procesamiento de los lobos marinos (Carrara, 1952). caño de hierro", con el cual se reducía a la presa y el segundo portando el pico, con el cual se la ultimaba. Se puede comparar esta descripción con la ofrecida por Quiroz (2007) para las cacerías de lobos realizadas en isla Mocha en épocas contemporáneas. Allí el procedimiento de encierro era similar y la matanza también era realizada por dos cazadores, aunque en este caso en lugar de un "pico" se utilizaba una lanza. Existen menciones y fotografías de matanzas realizadas con armas de fuego (Fig. 2), pero aparentemente dejaron de ser comunes, posiblemente por su costo, hacia los tiempos en que funcionaba la factoría de bahía Thetis.

2 Grupo de lobos marinos separados y acorralados por la "comparsa" para su arreo y muerte en un lugar apropiado (Carrara, 1952). 


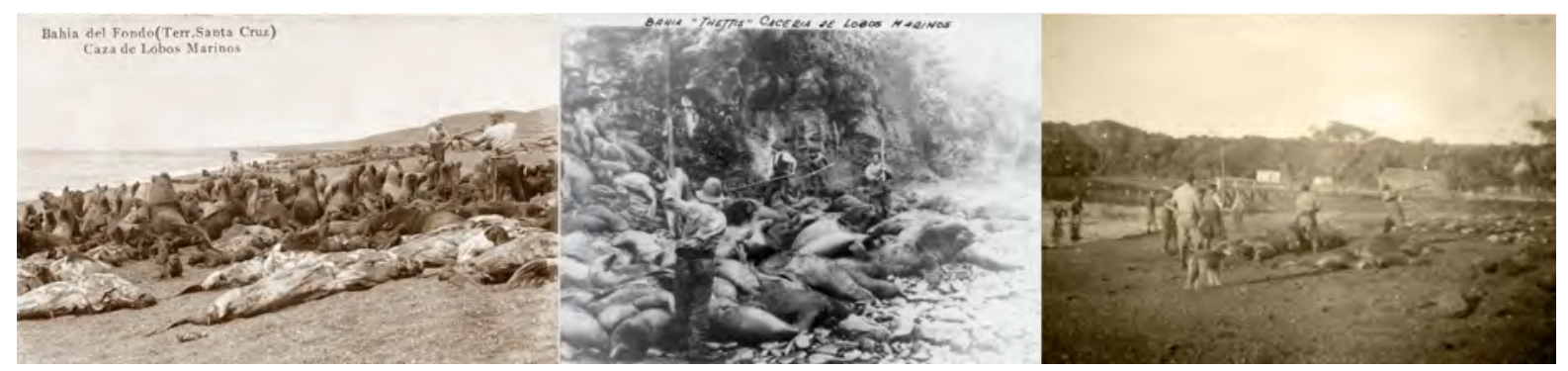

Fig. 2. Izquierda: antigua postal que ilustra las cacerías de pinnípedos realizadas en la actual provincia de Santa Cruz, nótense los animales a los que ya se les ha extraído el cuero en el mismo lugar de la matanza, visibles al pie de la imagen y el uso de armas de fuego para matarlos (fotografía Federico Kolhmann). Centro: fotografía histórica de miembros de una "comparsa" realizando las tareas de encierro y arreo en la zona de bahía Thetis (fotografía archivo del Museo del Fin del Mundo). Derecha: tareas de matanza de animales realizada en el interior de la bahía Thetis (fotografía archivo Fundación Histarmar).

Respecto del procesamiento, en animales adultos, los cueros se extraían con el panículo adiposo, que podía alcanzar hasta unos $7 \mathrm{~cm}$ de espesor. Una vez extraído, el cuero se extendía sobre una tabla sostenida por caballetes a unos $45^{\circ}$ y se procedía a extraer el panículo adiposo adherido a la parte interna del cuero con cuchillas; este procedimiento se denominaba "fichado". El resultado, una vez concluida esta etapa del trabajo, era la obtención del cuero por un lado y el tejido graso que era procesado para la obtención del aceite por otro (Carrara, 1952). Los cueros de los animales más jóvenes eran destinados a la industria peletera y los de los adultos a la talabartería o marroquinería. Los cueros eran lavados y sumergidos entre 24 y 48 horas en una solución de agua salada y luego, previo al estibado, eran escurridos. El estibado se realizaba intercalando los cueros con sal para su conservación, luego eran enviados por barco a las curtiembres que se ubicaban principalmente en la ciudad de Buenos Aires y alrededores.

El otro producto elaborado en esta factoría era el aceite, el cual era obtenido a partir del tejido extraído mediante el desgrasado de los cueros realizado durante el "fichado". Según Carrara (1952), si bien era posible obtener aceite de otras regiones del animal, estos procedimientos no se realizaban en nuestro país, por lo cual debemos asumir que el resto del cuerpo de las presas era descartado. El mismo autor señala que toda la producción de aceite de lobo marino proveniente de las factorías argentinas era absorbida por la industria nacional del cuero (Carrara, 1952, p.142). Sin embargo, otros autores han sostenido que el aceite de pinnípedos también fue destinado a cubrir la gran demanda generada durante la Segunda Guerra Mundial para la fabricación de lubricantes pesados (Zanola, 2002).

El destilado del aceite podía realizarse por medio de dos procedimientos: "fuego directo" o "vapor directo a presión". El primero consistía en calentar el tejido graso en algún tipo de contenedor de hierro o acero, utilizando leña, las osamentas de animales o cualquier otro combustible. Mediante este procedimiento, más rudimentario y menos controlado, no era posible obtener aceite de buena calidad. El otro procedimiento implicaba la utilización de una caldera en la cual se calentaba agua, cuyo vapor era inyectado a digestores donde se fundían los trozos de tejido graso. Este equipamiento era el utilizado en la factoría de bahía Thetis (Fig. 3).

Los restos de las instalaciones principales de la factoría se encuentran en la costa occidental de bahía Thetis; allí se emplazan las calderas, el depósito de cueros, muelles y otras construcciones (Figs. 3 y 4). Carlos Vairo realizó una serie de relevamientos en la costa norte de Península Mitre durante las décadas de 1980 y 1990, dando a conocer descripciones y fotografías de los restos de la factoría (Vairo, 2014). En comparación con aquel registro, estas dependencias se encuentran en avanzado estado de destrucción, en la Fig. 4 se puede observar la posición de lo relevado en la campaña de 2011 y en la Fig. 3 el estado de algunas de las instalaciones mencionadas.

Además de las instalaciones emplazadas en la bahía, en los alrededores observamos la existencia de otras evidencias y sitios que podrían haber estado vinculados a las tareas realizadas en la factoría. Por ejemplo, en la zona del golfo San Vicente se encuentran los restos derrumbados de una construcción precaria y algunos relatos transmitidos oralmente por antiguos pobladores 


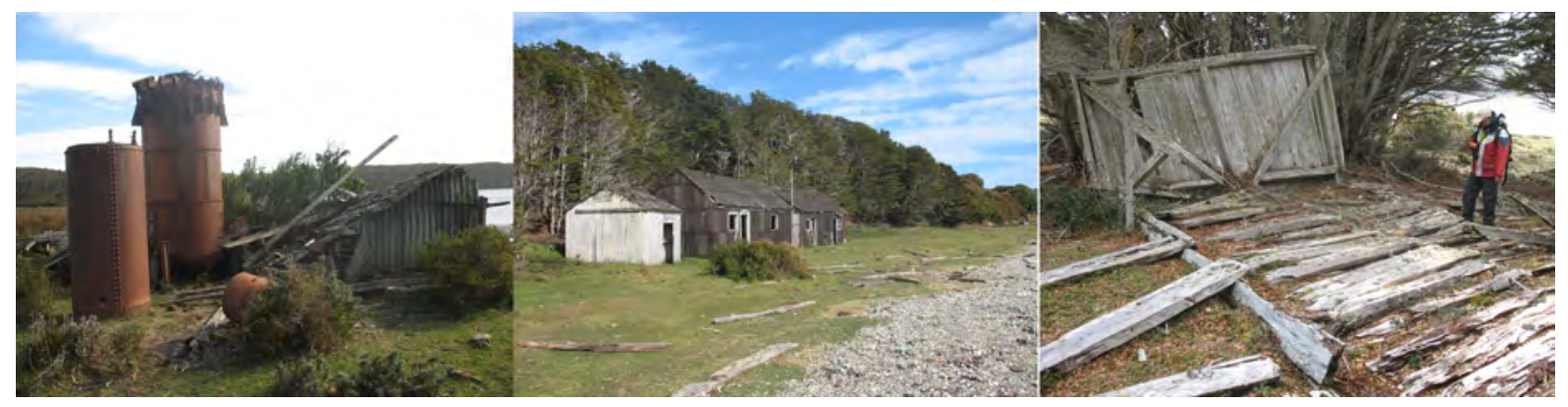

Fig. 3. Izquierda: restos de las calderas en las cuales se destilaba el tejido adiposo para la obtención de aceite y galpón semi-derrumbado. Centro: construcciones de función desconocida y ubicación del depósito de cueros. Derecha: construcción derrumbada en la zona del golfo San Vicente (todas las fotos fueron tomadas en noviembre de 2011).

de la zona señalan que originalmente el actual refugio denominado Tres Amigos era utilizado por los miembros de las comparsas que explotaban las loberías Las Chapas y Caleta Tres Amigos. Entre

la zona de este último apostadero y bahía Thetis se extiende un antiguo sendero por el cual se dice que eran efectuados los arreos de los animales en pie hasta las instalaciones de la factoría, donde

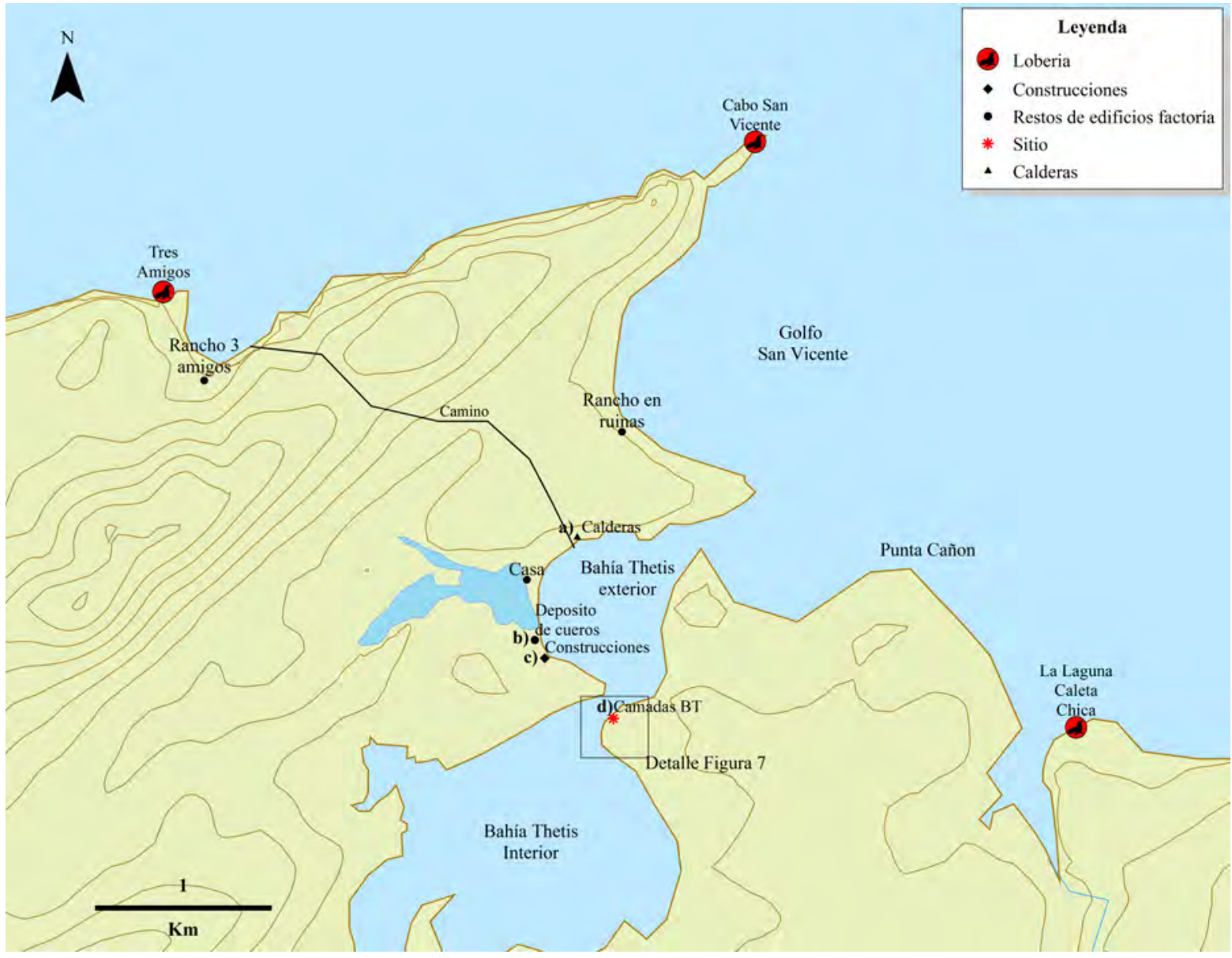

Fig. 4. Ubicación de las principales instalaciones registradas en bahía Thetis y de las camadas de huesos: a) restos de las calderas, b) depósito de cueros, restos de las calderas y un galpón derrumbado -ver Fig. 3-, cercanos a los restos de un muelle, c) construcciones de función desconocida y d) emplazamiento de las camadas de huesos (ver detalle en Fig. 7). 
se les daba muerte y se procesaban (Figs. 3 y 4). Asimismo, hemos registrado un sitio ubicado sobre un acantilado en cercanías de cabo San Diego, en el cual observamos la presencia de restos de pinnípedos semienterrados y otros visibles en un perfil, entre los cuales se hallaron cráneos con el mismo tipo de perforación en la zona parietal que los hallados en las camadas de huesos (ver más adelante y Fig. 10). Es destacable que en este sitio no se registraran huesos de otras especies, ni valvas, así como tampoco restos líticos u otra evidencia que nos permitiera asignarlos a ocupaciones de los grupos cazadores-recolectores que habitaron la región (sitio 304 en Vázquez, 2017, pp. 194-195).

\section{METODOLOGÍA}

El sitio fue visitado en dos oportunidades, en las cuales se realizaron relevamientos expeditivos en cada campaña. La primera de ellas se realizó en el marco del Programa Arqueológico Costa Atlántica (PACA) (Vázquez et al. 2010, 2013; Vázquez \& Santiago, 2014; Vázquez, 2017). La segunda, en marzo de 2017, tuvo por objetivo realizar un muestreo específico sobre la acumulación ósea en el marco de un programa de estudios arqueológicos y paleoecológicos para la margen sur de Tierra del Fuego (Zangrando et al. 2014).

El sitio fue detectado durante la primera campaña y, si bien se conocían algunas menciones referidas a grandes acumulaciones de huesos de pinnípedos producto de las actividades de la factoría (Winograd, 2008), no se contaba con descripciones o fotografías que permitieran tener una noción de su escala y características. Pese a no estar incluido entre los objetivos específicos del proyecto, una vez detectadas estas acumulaciones óseas y dada su singularidad, se decidió destinar parte del esfuerzo a efectuar un relevamiento preliminar. En tal sentido, se definió una estrategia de muestreo que nos permitió obtener una

3 Los mapeos de la extensión de las camadas de hueso se realizaron en la primera medición en el año 2011 con el GPS de marca Thales MobileMapper y la segunda toma de los perimetros de las camadas en 2017 con el GPS marca Garmin GPSmap 62s. Ambos GPS tienen errores horizontales de fábrica de +/- 3 metros. El error horizontal ha sido reducido a través del tiempo ya que se han incorporado satélites con lo cual las triangulaciones son más precisas. Actualmente no se aplica el error inducido, primera aproximación al sitio e identificar cuatro acumulaciones discretas de diferentes extensiones (Vázquez \& Santiago, 2014). Las áreas de cada una de las acumulaciones fueron mapeadas mediante GPS y se plantearon 5 muestreos de $1 \times 1$ metro: dos de ellos en la denominada Camada 1, la de mayor extensión, y una cuadrícula en cada una de las camadas restantes (Figs. 4B y 4C; Fig. 5). Aunque se constató la presencia de huesos enterrados en tres de las cinco cuadrículas, solamente se cuantificó y analizó el material de superficie. En estas unidades de muestreo se cuantificaron todos los especímenes y se realizaron identificaciones taxonómicas y anatómicas in situ, incluyendo criterios de lateralidad, tamaño y maduración. Las estimaciones taxonómicas y anatómicas fueron realizadas en el laboratorio, para ello se utilizaron las medidas convencionales en análisis zooarqueológicos: NISP, MNI, MNE, MAU y MAU\% (Lyman, 1994; Mengoni Goñalons, 1999, entre otros). Desde el punto de vista tafonómico, se inspeccionaron tibias, costillas y cúbitos -por ser elementos correspondientes a distintas regiones anatómicas- con el fin de identificar alteraciones por meteorización y modificaciones por carnivoros, roedores y raíces (Behrensmeyer, 1978; Binford, 1981; Lyman, 1994, entre otros). Asimismo, se buscaron huellas de corte, raspado, evidencia de fracturas, negativos de lascados y alteraciones por fuego (Lyman, 1994; Fisher, 1995; Mengoni Goñalons, 1999).

Durante la segunda campaña se delimitaron nuevamente las extensiones de las cuatro acumulaciones utilizando $\mathrm{GPS}^{3}$ y se efectuó un muestreo cuya finalidad fue generar un reservorio de especímenes que pudiera ser analizado con mayor profundidad en el laboratorio. El estudio de estos especímenes nos permitió conocer la composición taxonómica y los grupos de sexo y edad de los individuos representados en esa acumulación. Así como efectuar estudios químicos y biológicos que permitieron evaluar

con lo cual la precisión intrínseca del sistema GPS depende del número de satélites visibles en un momento y posición determinados (en nuestro caso siempre tomamos los datos con el máximo PDOP (Position Dilution of Precision), este dato muestra la distribución en el cielo de los satélites y la cantidad de satélites disponibles). Con esas salvedades pueden obtenerse precisiones inferiores a 2,5 metros en el 95\% del tiempo. 
el comportamiento pasado de las poblaciones de pinnípedos frente a la presión ejercida por la explotación industrial (Nye et al. 2018).

En este segundo muestreo, y para no replicar observaciones sobre un mismo individuo, se optó inicialmente por muestrear hemimandíbulas izquierdas que preferentemente conservaran el colmillo. Al poco tiempo de iniciar una recuperación sistemáticamente así definida desde el extremo oriental de las acumulaciones óseas, se observó un sesgo hacia la recolección de elementos grandes presumiblemente correspondientes a machos adultos y subadultos, posiblemente debido a cuestiones de visibilidad y preservación. Entonces, para ampliar el espectro e incluir ejemplares pertenecientes a otras categorías, como hembras y ejemplares más jóvenes, también se buscaron intencionalmente muestras de hemimandíbulas medianas-chicas sin considerar la lateralidad. Para obtener otra referencia sobre los grupos de edad representados en la acumulación, se optó también por muestrear fémures de ambas lateralidades de distintos tamaños y con distintos estados de fusión ósea, que nos permitieran contar con un conjunto de ejemplares de ambos sexos representativo de las categorías "fusionados", "semi-fusionados" y "sin fusionar". Para determinar la asignación a Otaria se midió el "ancho mandibular", criterio propuesto por Crespo (1984), en aquellos especímenes cuya completitud así lo permitió. Para la determinación de clases de edad a partir de los fémures se utilizaron los criterios propuestos por Borella et al. (2013).

\section{RESULTADOS}

\section{Descripción de las camadas de huesos de bahía Thetis}

Sobre la margen oriental de la angostura que separa la bahía exterior de la interior de bahía Thetis se encuentra emplazado un depósito conformado por grandes acumulaciones de huesos de pinnípedos. Sobre la base del relevamiento realizado en 2011, el sitio fue interpretado como producto de las actividades de matanza y procesamiento desarrolladas en la factoría. En esa oportunidad se propuso que este notable depósito sería producto de un proceso de acumulación secundaria ocasionado por la acción de las mareas que habría transportado hasta alli carcasas o segmentos anatómicos en distinto grado de desarticulación (Vázquez \& Santiago, 2014). En función de su disposición y su densidad relativa, en los registros efectuados en 2011 y 2017 se observaron cuatro camadas diferenciadas, dispuestas en forma paralela a la costa, sobre y por detrás de la berma de tormenta (Figs. 5 y 6). Es necesario mencionar que, si bien las extensiones de estas acumulaciones fueron definidas por presentar limites relativamente claros en superficie mediadas también por la densidad de huesos, la dispersión de especímenes óseos puede ser mayor que las acumulaciones discretas señaladas en la Fig. 6. Elementos dispersos han sido registrados a decenas de metros hacia el interior, en sectores totalmente vegetados, tanto en superficie como en proceso de enterramiento. Igualmente, en sectores distales de la playa, se observaron huesos completamente enterrados, incluso algunos elementos en posición articulada en los perfiles expuestos de la escarpa de erosión. Asimismo, durante la última campaña registramos un segmento de esqueleto enterrado en la playa de grava, a pocos metros de las camadas de huesos (Fig. 7). Esta carcasa fue detectada al observarse un cráneo semienterrado, que al ser excavado pudo comprobarse que se encontraba articulado con la mandíbula, el segmento cervical de la columna y uno de sus miembros anteriores. Dadas las limitaciones de tiempo y de capacidad de transporte de materiales no se continuó con la excavación, por lo cual no se descarta que esta carcasa presente un grado de completitud aún mucho mayor.

La Camada 1 es la más extensa y la que presenta mayor densidad, incluso en algunos espacios centrales muestra acumulaciones que conforman pilas de especímenes superpuestos (Figs. 5A y 5B). Sus límites fueron registrados en las campañas de 2011 y 2017, estimándose superficies de $460 \mathrm{~m}^{2}$ y $214 \mathrm{~m}^{2}$ respectivamente. Inmediatamente hacia el interior de la bahía, separada por unos tres metros, se delimitó la Camada 2. Esta es mucho más pequeña que la primera, alcanzando una superficie de $80 \mathrm{~m}^{2}$ según las estimaciones realizadas en 2011 y también mostró una reducción en 2017, con una superficie de $47 \mathrm{~m}^{2}$. No obstante su alta densidad y cercanía a la Camada 1 hacen suponer que ambos 


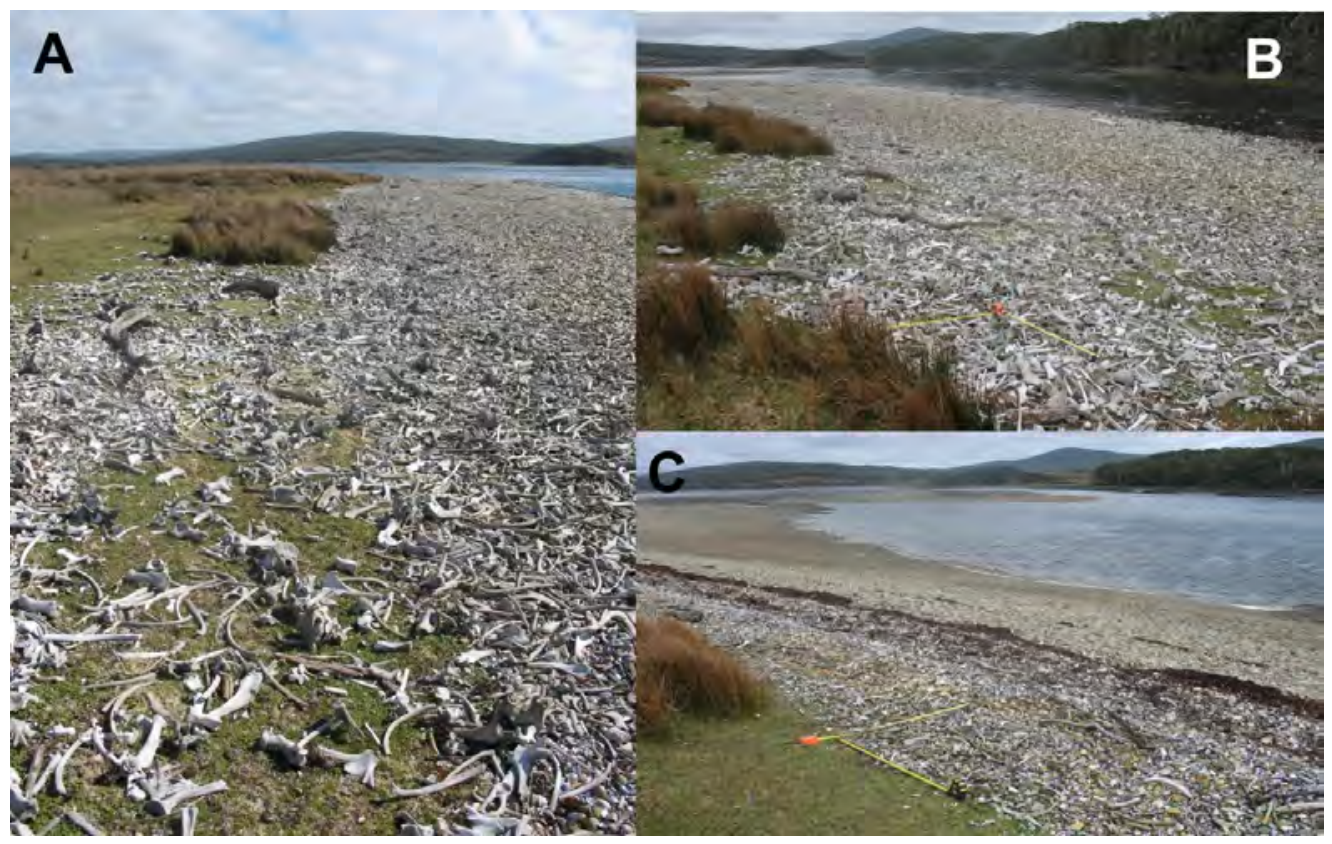

Fig. 5. Camadas de huesos. A: Vista general de la Camada 1. B: Camada 1 con la ubicación de la cuadrícula de muestreo 1. C: Camada 3 con la ubicación de la cuadrícula de muestreo 4 (fotos tomadas en 2011).

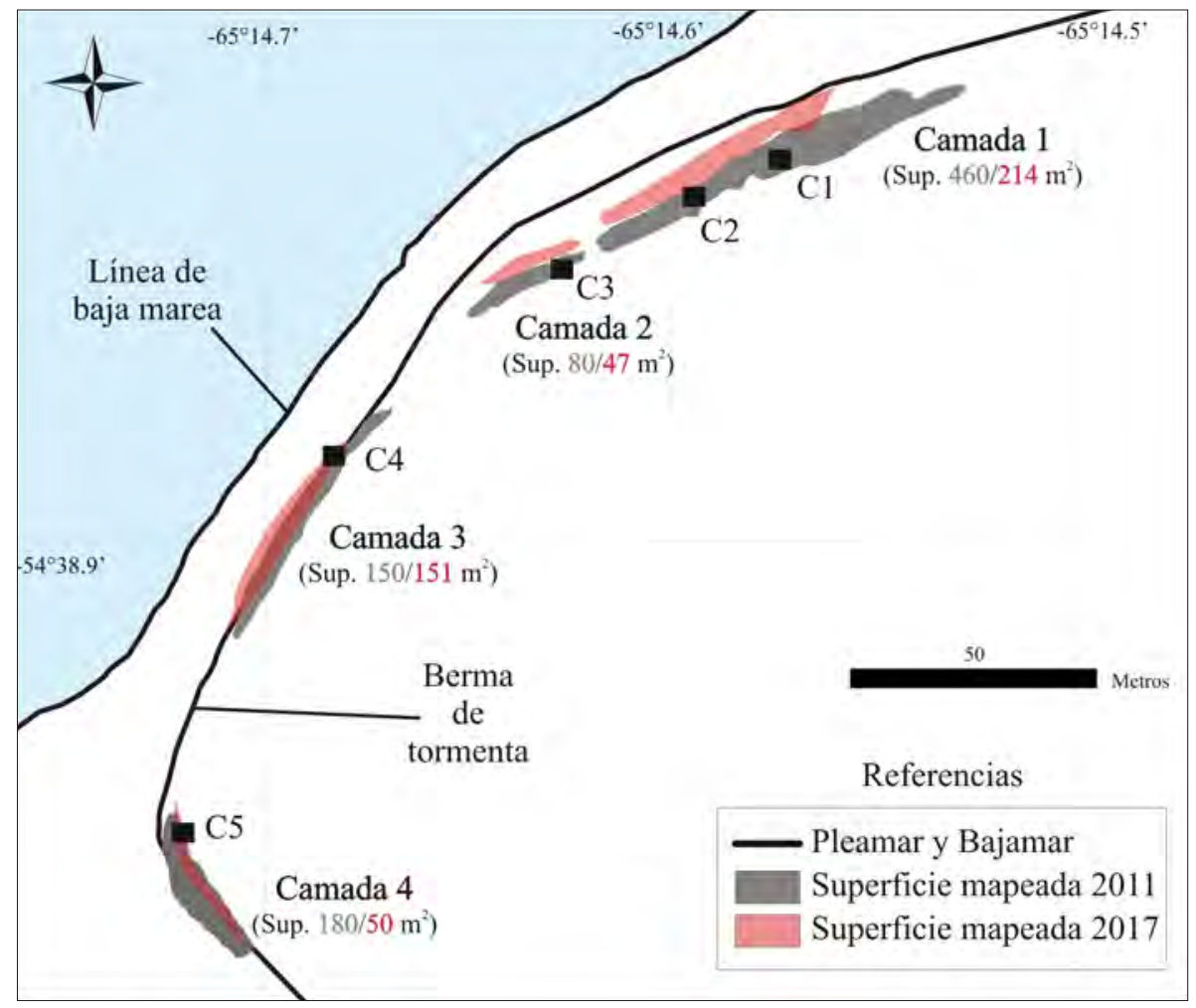

Fig. 6. Mapa de planta mostrando la ubicación de las camadas de huesos (tanto la posición en 2011 como en 2017) y las cinco cuadrículas analizadas. 


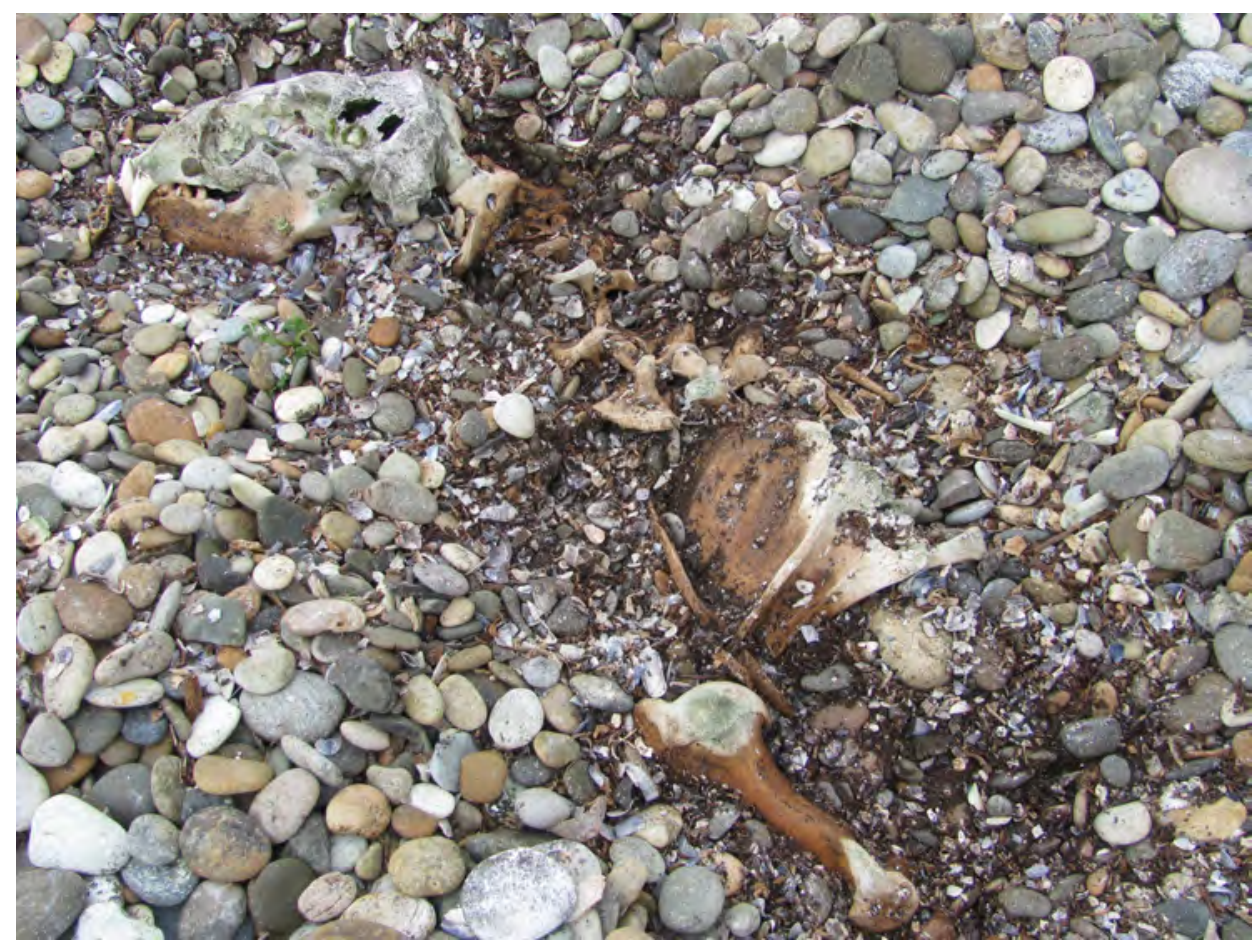

Fig. 7. Esqueleto de lobo marino articulado y sepultado por gravas de la playa (foto tomada en 2017).

depósitos podrían estar vinculados. Las restantes acumulaciones se emplazan en posición interior respecto de las anteriores y exhiben una densidad de restos notablemente menor. La Camada 3, separada por $23 \mathrm{~m}$ de la Camada 2, alcanzó una superficie de $150 \mathrm{~m}^{2}$ según el relevamiento de 2011 (Fig. 5C) y de $151 \mathrm{~m}^{2}$ en 2017 y la Camada 4 , separada por $37 \mathrm{~m}$ de la anterior, unos $180 \mathrm{~m}^{2}$, en 2011, y $50 \mathrm{~m}^{2}$ en 2017.

Independientemente de la potencial relación entre las Camadas 1 y 2 , estas dos acumulaciones presentan algunos rasgos en común, sin duda el más notable es la mayor densidad de especímenes en comparación con las acumulaciones más internas con respecto a la bahía. A su vez se encuentran situadas detrás de la berma de tormenta, lo que estaría indicando un ámbito de mayor energía en el momento de su depositación. Por su parte, las dos acumulaciones internas -Camadas 3 y 4- muestran una densidad de elementos decreciente hacia los sectores internos y su emplazamiento sobre la berma de tormenta, sugiere condiciones de menor dinámica de mareas que el ocupado por las acumulaciones externas (ver Figs. 5 y 6).

\section{Análisis zooarqueológico y tafonómico}

Se cuantificaron 2.141 especímenes en las cinco cuadrículas de muestreo analizadas, de los cuales 324 restos $(15,1 \%)$ no pudieron ser determinados, en su mayoría pequeños fragmentos de huesos de mamíferos carentes de rasgos diagnósticos, que a juzgar por la composición general del conjunto la mayor proporción deberían corresponder a pinnípedos. El NISP total de las cinco cuadrículas es de 1.817, entre los cuales $1.772(97,5 \%)$ corresponden a pinnípedos. Solo 45 especímenes, un 2,5\% del NISP corresponde a restos de otros taxa. En la Tabla 1 pueden observarse los valores de NISP para todo el conjunto y los MNE estimados para pinnípedos. El MNI de pinnípedos para el total del conjunto es igual a 27 y fue estimado a partir del húmero derecho, la porción mejor representada en las cinco unidades de muestreo consideradas en conjunto.

Como fue mencionado, las cuadrículas 1 y 2 corresponden a la Camada 1. La cuadrícula 2 fue emplazada en uno de los sectores centrales de la Camada 1, pero no en el sector de mayor 
Tabla 1. Cuantificación taxonómica (NISP) y anatómica (MNE) de las muestras analizadas, discriminadas por cuadrículas.

\begin{tabular}{ccccccccc}
\hline & & \multicolumn{3}{c}{ Pinnipedia } & & L. guanicoe & Ave & Bos taurus \\
& NISP - (\%) & MNE & NISP/MNE & NISP - (\%) & NISP - (\%) & NISP - (\%) & NISP (t) & Indet - (\%) \\
\hline Cuadrícula 1 & $336(99,4)$ & 234 & 1,43 & $2(0,6)$ & 0 & 0 & 338 & $28(7,6)$ \\
Cuadrícula 2 & $657(99,1)$ & 403 & 1,63 & $3(0,4)$ & $3(0,4)$ & 0 & 663 & $79(10,6)$ \\
Cuadrícula 3 & $440(98,2)$ & 245 & 1,79 & $1(0,2)$ & $7(1,5)$ & 0 & 448 & $93(17,2)$ \\
Cuadrícula 4 & $230(90,5)$ & 79 & 2,91 & $1(0,4)$ & $22(8,6)$ & $1(0,4)$ & 254 & $72(22,1)$ \\
Cuadrícula 5 & $109(95,6)$ & 64 & 1,7 & $1(0,8)$ & $4(3,5)$ & 0 & 114 & $52(31,3)$ \\
\hline TOTAL & $1772(97,5)$ & 1025 & 1,72 & $8(0,4)$ & $36(1,9)$ & $1(0,05)$ & 1817 & $324(15,1)$ \\
\hline
\end{tabular}

densidad donde los huesos formaban una pila. Aun así, resultó ser la unidad de muestreo que mayor densidad presentó y donde se registraron los valores más altos de NISP y MNE de todo el conjunto. Le siguen en densidad la cuadrícula 3 (Camada 2) y la cuadrícula 1 (Camada 1), mientras que las cuadrículas 4 y 5 presentan valores notablemente menores (Tabla 1). Todos los huesos se observaron totalmente desarticulados y dispuestos en forma caótica, sin registrarse posiciones articuladas entre los diferentes elementos. Como se señaló la densidad de restos en superficie disminuye hacia el sector interior de la bahía, otras tendencias que acompañan este patrón son la proporción de especímenes no identificados, la mayor frecuencia de restos más pequeños y el aumento de la relación NISP/MNE, lo cual sugiere un mayor grado de fragmentación a medida que nos movemos hacia los sectores interiores de la bahía (Tabla 1).

Se determinó que todas las hemimandíbulas recolectadas $(\mathrm{N}=101)$, así como la totalidad de los fémures $(\mathrm{N}=70)$ corresponden a Otaria flavescens. Respecto de los parámetros poblacionales de la muestra, la determinación de sexo fue realizada a partir del ancho mandibular (Crespo, 1984) y el perfil resultante indica una mayoritaria representación de machos $(\mathrm{N}=67)$, constituyendo el $66,4 \%$ de los especímenes analizados (Tabla 2 y Fig. 8). Las hembras representan solo un $16,8 \%(\mathrm{~N}=17)$ de la muestra. El 16,8\% ( $\mathrm{N}=17)$ restante corresponde a hemimandíbulas que no pudieron ser determinadas por sexo: cinco de ellas corresponden a cachorros y los restantes especímenes presentaban sus rasgos diagnósticos fragmentados. Si solo consideramos los especímenes que pudieron ser diferenciados por sexo la relación entre machos y hembras sería del $79,8 \%$ y $20,2 \%$ respectivamente (Fig. 8). Las edades de muerte de los especímenes no han podido ser definidas con suficiente resolución como para caracterizar un perfil etario representativo, ya que por el momento no hemos realizado análisis que nos permitan arribar a determinaciones de grano fino (e.g. análisis de anillos de crecimiento). Para estas determinaciones se tuvieron en cuenta los criterios propuestos por Crespo $(1984,1988)$ y por Borella y coautores (2013). En cuanto a la categoría "< de un año", dentro de la cual fueron incluidos algunos individuos $(\mathrm{N}=5)$, esta fue determinada para aquellas hemimandíbulas en las cuales la erupción de los caninos era incompleta (Crespo, 1984). Las categorías etarias identificadas a partir de los grados de fusión en fémures (Tabla

Tabla 2. Determinación de sexo y edad en hemimandíbulas y fémures recolectados en la campaña 2017.

\begin{tabular}{ccccccccc}
\hline & \multicolumn{3}{c}{ Hemimandíbulas } & \multicolumn{3}{c}{ Fémures } \\
& Machos & Hembras & ND & Total & Machos & Hembras & ND & Total \\
\hline < de un año & & & 5 & 5 & & & 2 & 2 \\
Sub Adult (no fus) & & & & & 17 & 3 & 20 \\
Adult (semi fus) & 67 & 17 & 12 & 96 & 16 & 10 & 26 \\
Adult (fusionado) & & & & & 4 & 18 & 22 \\
\hline & 67 & 17 & 17 & 101 & 37 & 31 & 2 & 70 \\
\hline
\end{tabular}




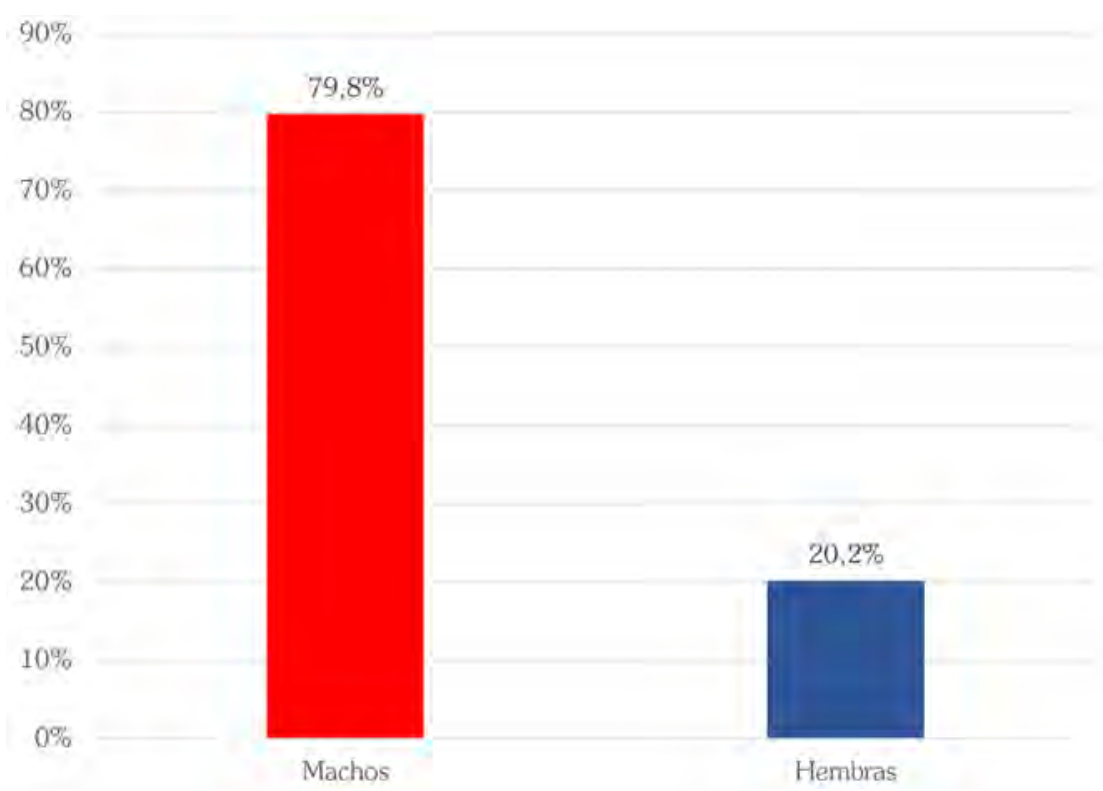

Fig. 8. Representación porcentual de machos y hembras determinados a partir de las hemimandíbulas $(\mathrm{N}=84)$.

2) nos permiten indicar que los conjuntos están compuestos por un amplio rango de edades, dado que se identifican tanto individuos juveniles como adultos para ambos sexos. Como ya se señaló, también se destaca la presencia de cachorros en la muestra analizada.

Los elementos mejor representados en el conjunto de las 5 cuadrículas son los huesos largos de ambos miembros (húmero, radio, fémur y tibia) y el cráneo; le siguen en abundancia atlas/ axis, costillas, pelvis y peronés y presentan bajas frecuencias las vértebras, esternebras y otros huesos de tamaño pequeño, como rótulas, astrágalos y calcáneos (Tabla 3). El análisis de estimaciones de abundancia anatómica por cuadrícula muestra una cierta variabilidad, aunque la tendencia general es una mejor representación de los miembros, sobre todo en las cuadrículas 1 a 3, las de mayor densidad. En algunos casos, la representación de elementos de la cabeza, atlas/axis y costillas también es relativamente alta (Tabla 3). Por el contrario, el resto del esqueleto axial presenta valores bajos de MAU\%. Esto sugiere una situación de pérdida de elementos mediada por la densidad, aunque los perfiles resultantes también podrían estar influidos por los procedimientos empleados para estimar la abundancia de elementos pares de los miembros o únicos como atlas y axis, en comparación con aquellos utilizados para cuantificar regiones como la torácica, lumbar, etc. (ver discusión en Vázquez, 2015, pp. 257-259). A fin de evaluar el grado de similitud entre los perfiles anatómicos de cada una de las cuadrículas, se realizó una matriz de correlación utilizando el test Rho de Spearman, comparando los valores de MAU\% de cada una de ellas. En general los perfiles anatómicos son similares entre sí, con excepción de la cuadrícula 1 que se diferencia claramente de las demás (Tabla 4). Esta cuadrícula no mostró niveles de correlación significativos con ninguna de las restantes unidades de muestreo mientras que, por el contrario, las correlaciones efectuadas entre los MAU\% de cuadrículas 2 a 5 arrojaron resultados positivos. Entre ellos se destacan los altos niveles de significación resultantes de la comparación entre los conjuntos de las cuadrículas 2 y 3,3 y 4, 3 y 5 .

En la Fig. 9 se puede observar el perfil de meteorización (Behrensmeyer, 1978) de la muestra analizada en las cinco cuadrículas, obtenido a partir de la observación de tres elementos testigo: húmeros, tibias y costillas ( $\mathrm{N}=163$ ) (Tabla 5). Pudo verificarse la presencia mayoritaria de estadios avanzados, no registrándose especímenes en los estadios 0 y 1 y solo 7 especímenes $(4,3 \%)$ en el estadio 2. El estadio mejor representado es el 4 con 109 especímenes $(66,9 \%)$. En términos generales, 


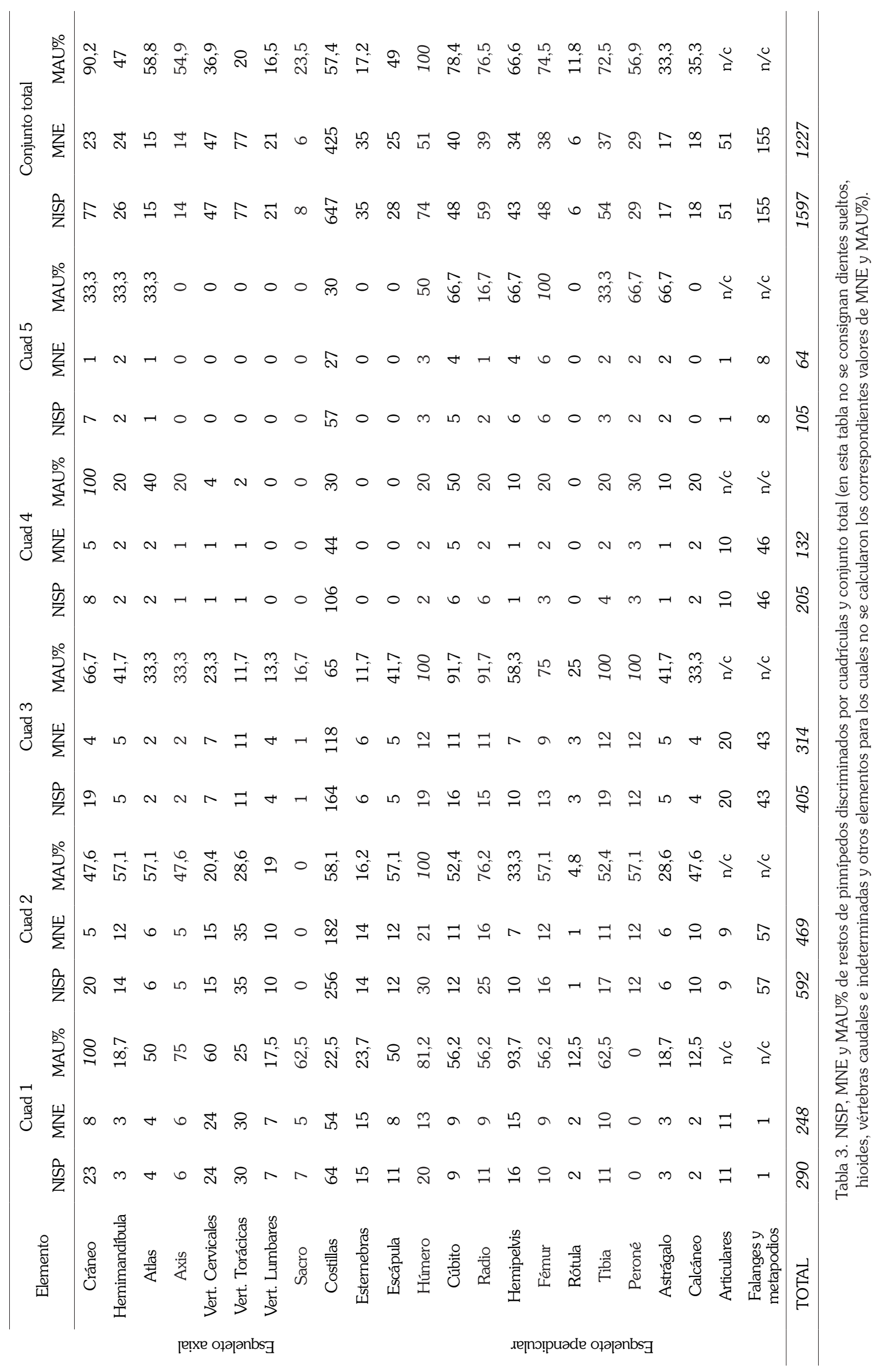


Tabla 4. Matriz de correlación (Rho de Spearman) entre los MAU\% de los conjuntos de pinnípedos procedentes de cada una de las cuadrículas, los resultados significativos se resaltan en negrita.

\begin{tabular}{ccccc}
\hline & Cuad 1 & Cuad 2 & Cuad 3 & Cuad 4 \\
\hline Cuad 2 & $\mathrm{r}=0.09652 / \mathrm{P}=0.6773$ & & & \\
Cuad 3 & $\mathrm{r}=0.2655 / \mathrm{P}=0.2447$ & $\mathrm{r}=0.7533 / \mathrm{P}<0.0001$ & & \\
Cuad 4 & $\mathrm{r}=0.1834 / \mathrm{P}=0.4261$ & $\mathrm{r}=0.6483 / \mathrm{P}=0.0015$ & $\mathrm{r}=0.6722 / \mathrm{P}=0.0008$ & \\
Cuad 5 & $\mathrm{r}=0.1721 / \mathrm{P}=0.4558$ & $\mathrm{r}=0.4928 / \mathrm{P}=0.0232$ & $\mathrm{r}=0.7536 / \mathrm{P}<0.0001$ & $\mathrm{r}=0.6036 / \mathrm{P}=0.0038$ \\
\hline
\end{tabular}

no se observaron diferencias significativas entre cuadrículas respecto a los estadios de meteorización, aunque la cuadrícula 5 muestra una mayor homogeneidad de frecuencias y una moda menos marcada, lo que sugiere una acumulación con tendencia más atricional que en el resto de las cuadrículas.

No fueron registradas huellas de corte o puntos de impacto en ningún caso. Las únicas modificaciones que consideramos antrópicas son los orificios observados en la gran mayoría de los cráneos, que se corresponden con la descripción, antes mencionada, sobre el procedimiento mediante el cual se daba muerte a los animales (Fig. 10). Tampoco fueron observadas marcas de raíces o roedores y solo en unos pocos casos se verificó la presencia de modificaciones asignables a la acción de carnívoros. Sin embargo, es necesario tener en cuenta que los avanzados estadios de meteorización pudieron enmascarar otros tipos de modificaciones sobre las superficies óseas. Es interesante mencionar aquí que Cartajena y Labarca (2007) interpretan las marcas de corte identificadas en hemimandíbulas como producto del cuereo de los animales, una expectativa que se planteaba para este caso, en especial para los ejemplares subadultos.

Los resultados de las frecuencias anatómicas calculados para cada una de las cuadrículas de muestreo y para el conjunto total fueron comparados con los valores de densidad mineral ósea (DMO) publicados por Borella y colaboradores (2007), utilizando el test Rho de Spearman (Tabla 6). Se compararon 19 pares de valores $\mathrm{y}$, a excepción de las cuadrículas $1 \mathrm{y}$ 5 , se obtuvieron correlaciones significativas de tendencia positiva, lo que sugiere una mayor preservación de elementos de alta densidad y una baja de aquellos menos densos, consecuencia de la acción de procesos atricionales. No

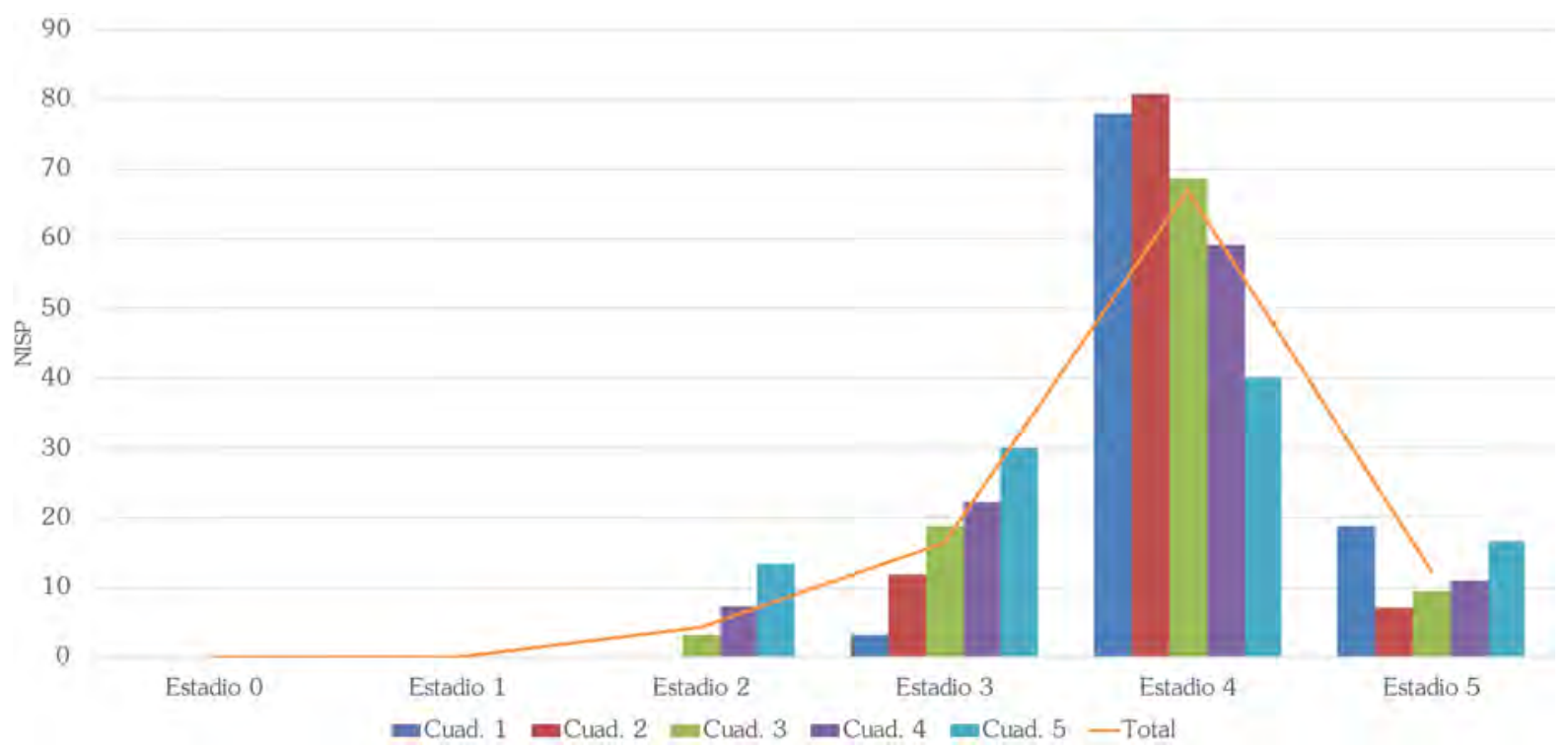

Fig. 9. Perfiles de meteorización de las cuadrículas muestreadas. 
Tabla 5. Cantidades de especímenes (NISP y \%NISP), discriminados por cuadrícula, estadio de meteorización.

\begin{tabular}{cccccccc}
\hline & Estadio 0 & Estadio 1 & Estadio 2 & Estadio 3 & Estadio 4 & Estadio 5 & Total \\
\hline Cuad. 1 & 0 & 0 & 0 & $1(3,1 \%)$ & $25(78,1 \%)$ & $6(18,8 \%)$ & 32 \\
Cuad. 2 & 0 & 0 & 0 & $5(11,9 \%)$ & $34(80,9 \%)$ & $3(7,1 \%)$ & 42 \\
Cuad. 3 & 0 & 0 & $1(3,1 \%)$ & $6(18,8 \%)$ & $22(68,7 \%)$ & $3(9,4 \%)$ & 32 \\
Cuad. 4 & 0 & 0 & $2(7,4 \%)$ & $6(22,2 \%)$ & $16(59,2 \%)$ & $3(11,1 \%)$ & 27 \\
Cuad. 5 & 0 & 0 & $4(13,3 \%)$ & $9(30 \%)$ & $12(40 \%)$ & $5(16,6 \%)$ & 30 \\
\hline Total & 0 & 0 & $7(4,3 \%)$ & $27(16,5 \%)$ & $109(66,9 \%)$ & $20(12,3 \%)$ & 163 \\
\hline
\end{tabular}

Tabla 6. Comparación de valores de densidad mineral ósea con los MAU\% correspondientes a cada una de las cuadrículas relevadas.

\begin{tabular}{cccc}
\hline & r Spearman & $\mathrm{P}$ & \\
\hline Cuad 1 vs. DMO & -0.1799 & 0.4612 & No significativa \\
Cuad 2 vs. DMO & 0.6799 & 0.0014 & Muy significativa \\
Cuad 3 vs. DMO & 0.7302 & 0.0004 & Extremadamente significativa \\
Cuad 4 vs. DMO & 0.4750 & 0.0398 & Significativa \\
Cuad 5 vs. DMO & 0.4552 & 0.0502 & No muy significativa \\
Conj. total vs. DMO & 0.5055 & 0.0273 & Significativa \\
\hline
\end{tabular}

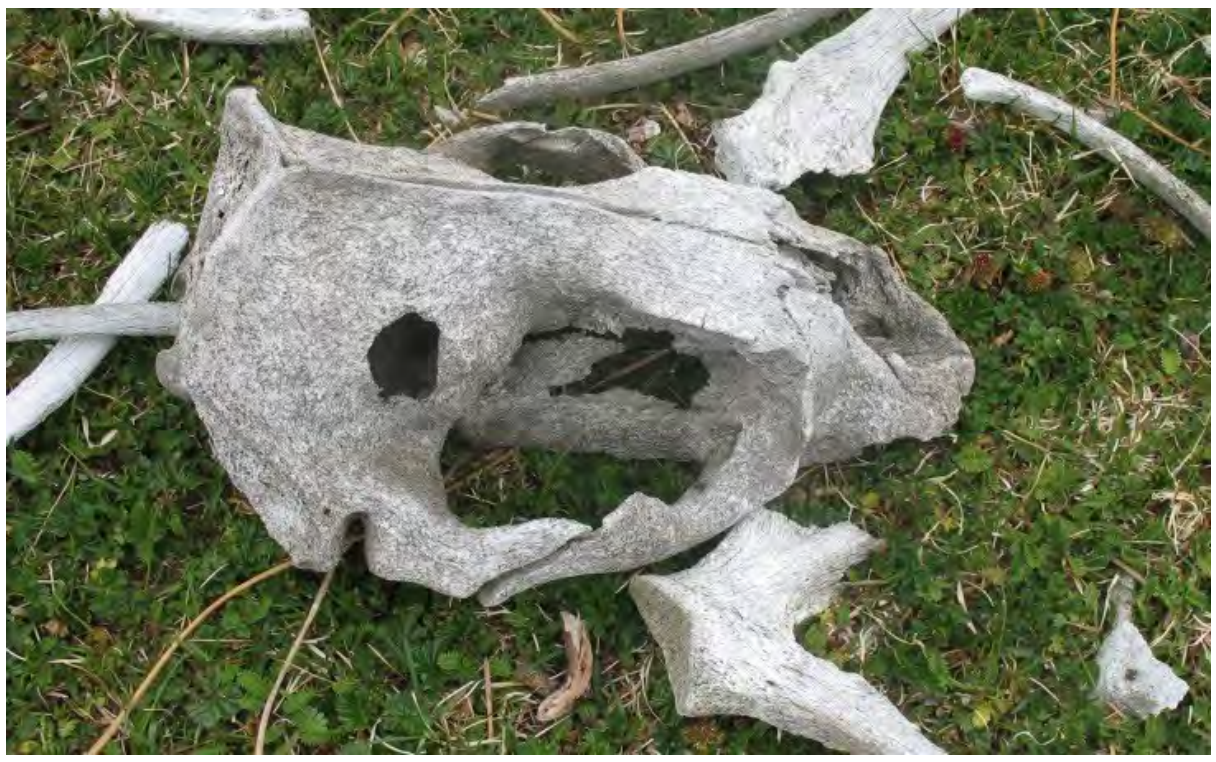

Fig. 10. Cráneo de pinnípedo con orificio sobre región parietal, interpretado como producto del golpe aplicado para dar muerte a los animales.

obstante, perfiles similares también podrían ser producto de procesos de transporte diferencial, ya que los huesos porosos, livianos y pequeños son más susceptibles de ser transportados a mayores distancias por agentes hídricos que los huesos pesados (Voorhies, 1969; Aslan \& Behrensmeyer, 1996; Liebig et al. 2003). Estos resultados permiten establecer un escenario de cierta equifinalidad para la interpretación de las frecuencias anatómicas representadas, ya que las 
bajas frecuencias de huesos poco densos podrían estar relacionadas tanto con los procesos de destrucción como con el transporte diferencial.

\section{DISCUSIÓN Y CONSIDERACIONES FINALES}

El área de bahía Thetis se presenta como una localidad arqueológica de alta significancia, tanto desde el punto de vista de su potencial para la investigación como por sus valores patrimoniales. Los estudios arqueológicos orientados al estudio de las sociedades originarias que allí habitaron brindaron valiosa información sobre distintos aspectos (Lanata, 1995, 1996) y recientemente han sido retomados y ampliados (Vázquez, 2017). El caso de la factoría representa un contexto muy relevante para abordar temáticas relacionadas con las explotaciones loberas de mediados del siglo $\mathrm{XX}$, dado el grado de aislamiento de la localidad y la integridad que presentan algunos de sus emplazamientos.

Luego del análisis de las fuentes documentales y el material zooarqueológico interpretamos que las carcasas enteras o segmentadas habrían sido descartadas en diversos sectores de la bahía, como producto de la faena y luego transportadas hasta la playa por las corrientes; una vez desarticuladas fueron depositadas por las mareas extraordinarias y las tormentas en su posición actual. En relación con el potencial de movilidad de carcasas completas, resultan relevantes las observaciones de Schafer acerca del transporte postmortem de cetáceos en el Mar del Norte, que pueden mantenerse a flote por semanas a causa de los gases generados por la descomposición (Schafer, 1972, en Liebig et al. 2003).

El contexto analizado presenta grandes concentraciones de huesos en superficie. Consideramos que las acumulaciones óseas aquí descriptas se ajustan a las caracterizaciones generales de los contextos definidos como bonebeds, ya que algunas incluyen depósitos no sepultados (Behrensmeyer, 1991, 2007; Eberth et al. 2007b). Por otra parte, como se mencionó, se observaron especímenes enterrados bajo las cuadrículas de muestreo y también en sectores aledaños a las acumulaciones registradas en superficie, aunque por el momento desconocemos los límites, densidades y composición de los conjuntos a nivel subsuperficial. Siguiendo la clasificación propuesta por Rogers y Kidwell (2007), las camadas de huesos analizadas corresponden a concentraciones de macrofósiles, originadas por un agente físico, en este caso hidráulico, a partir del descarte intensivo efectuado por loberos dentro de la bahía a mediados del siglo XX y que pueden ser caracterizadas como monoespecíficas (sensu Behrensmeyer, 2007), ya que el 97,5\% de los especímenes corresponden a pinnípedos. Por otro lado, además de las observaciones realizadas en el campo, tanto las determinaciones efectuadas sobre hemimandíbulas como la información relativa a la composición de las loberías de la zona (Carrara, 1952; Schiavini \& Raya Rey, 2001), indican la presencia excluyente de Otaria flavescens, por lo cual podemos asumir que la mayor parte de los restos que componen el depósito corresponderían a esta especie.

Otro aspecto mencionado es que en muchos casos los depósitos de este tipo (e.g. acumulaciones de restos de muchos individuos a lo largo de líneas costeras) reflejan eventos de mortalidad masivos o de elevado número de individuos (Rogers \& Kidwell, 2007, p. 26). En el caso de bahía Thetis, si bien las actividades de explotación se extendieron por casi una década, podemos asumir que los altos niveles de matanza de animales en un área acotada y la escala de tiempo implicada, presentan una situación comparable en términos tafonómicos a un evento de muerte masiva.

La disposición de las acumulaciones óseas presenta una expresión lineal en su morfología, copiando la línea de máximas mareas en la playa de rodados (Figs. 5 y 7). Diversos autores mencionan que los restos y los depósitos de este tipo presentan una disposición tangencial a la línea de máximas mareas, situación que se corrobora en este caso. Además, los huesos se presentan totalmente desarticulados y se registró contacto entre elementos no relacionados anatómicamente, hecho que también ha sido asociado con un agente hidráulico (Eberth et al. 2007a). Tal distribución de los restos se ajusta a la morfología de una concentración generada por las mareas o por efecto del oleaje (Eberth et al. 2007a; Rogers \& Kidwell, 2007, pp.25-26). Esto no implica desconocer la posibilidad que en otros sectores de la bahía puedan existir acumulaciones densas generadas por el descarte directo de carcasas como 
producto de las actividades de faena. Como se indica anteriormente, se requieren exploraciones subsuperficiales para avanzar en una discusión más ajustada sobre estos procesos.

En cuanto a la distribución de los especímenes y su relación con los procesos de formación, las Camadas 1 y 2 presentan la mayor densidad por metro cuadrado, además de huesos de mayor tamaño y un mayor grado de completitud, tanto de las carcasas como de los elementos individuales. Asimismo, estas dos concentraciones se emplazan sobrepasando los niveles de la berma de tormenta, lo que sugiere que estos especímenes se habrian depositado en uno o varios eventos de máxima energía del mar, alcanzando cierto grado de estabilidad en aquellos casos establecidos sobre cotas más altas. Por su parte, las Camadas 3 y 4 presentan menor cantidad de restos por metro cuadrado y bajas frecuencias -e incluso ausenciasde algunas partes esqueletales. En este ámbito se depositaron restos más livianos y también fragmentos más pequeños. Ambas camadas de huesos están sobre la cota de las máximas mareas en un sector donde la evidencia geomorfológica y la propia distribución de los restos denotan una dinámica de menor energía.

Sobre la base de los dos mapeos realizados en 2011 y 2017 se puede observar una disminución en la superficie de todas las acumulaciones y un desplazamiento de las Camadas 1 y 2 hacia un nivel más bajo de playa, coincidentemente con la zona denominada de sobrelavado o de vaivén (Fig. 7). En cambio, en las Camadas 3 y 4 solo se observa una disminución de su superficie. Estas modificaciones, en un ambiente sumamente dinámico, resaltan el rol activo de las mareas y las tormentas en la formación y transformación de los conjuntos.

En relación con la información histórica, es importante recordar que los métodos de extracción de aceite se restringían al procesamiento del tejido adiposo obtenido durante el "fichado", lo cual permite inferir que, con excepción del cuero y el tejido adiposo subcutáneo, el resto del animal debería ser descartado sin más procesamiento.

En general, se observa una relación significativa entre las estimaciones de abundancia anatómica y la DMO. No obstante, no en todas las cuadrículas se observa esta tendencia. En este sentido, debemos destacar que las frecuencias anatómicas de los conjuntos procedentes de las cuadrículas 1 y 5 no coinciden con las expectativas de conservación diferencial de elementos más densos (Tabla 6). En consecuencia, los perfiles anatómicos no se ajustan del todo ni a las expectativas derivadas de la conservación diferencial mediada por la $\mathrm{DMO}$, ni a las de transporte diferencial. Todo lo cual está sugiriendo la existencia de una situación de equifinalidad, en la cual estarían actuando de manera simultánea y solapada distintos procesos en la conformación final de la muestra.

A partir de experimentos llevados a cabo en el East Fork River por Behrensmeyer y colaboradores se han observado tres situaciones con relación a los procesos de destrucción y transporte selectivo (Aslan \& Behrensmeyer, 1996, pp. 417-418): a) conjuntos óseos seleccionados que representan periodos cortos de tiempo; b) conjuntos conformados por huesos pesados de los miembros, que reflejan la destrucción diferencial durante el transporte o retrabajo de sedimentos, representarían intervalos más largos de tiempo; y c) conjuntos conformados por huesos livianos, que sugieren tiempos cortos. Los patrones de frecuencias anatómicas de los conjuntos de bahía Thetis no se ajustan del todo a ninguna de las situaciones descriptas por Aslan y Behrensmeyer, lo cual también sugiere dos alternativas: a) limitaciones de una experimentación realizada en ámbitos fluviales para interpretar procesos en ámbitos marítimos; $\mathrm{y}$ b) superposición de procesos de destrucción in situ y de transporte diferencial.

A modo de comparación, los resultados de los estudios tafonómicos sobre restos de pinnípedos publicados por Borella y Muñoz (2006) pueden resultar de interés. Los autores mencionados realizaron el análisis de cuatro conjuntos registrados a lo largo de transectas localizadas en el norte de la costa atlántica fueguina: dos provenientes de la zona de Cullen y otras dos de la zona de El Páramo. La primera observación que resulta de la comparación es la alta densidad registrada en las acumulaciones de bahía Thetis en comparación con los registros de Borella y Muñoz, quienes informan un máximo de 257 especímenes en una de las transectas de El Páramo de $580 \mathrm{~m}$ de extensión. En cuanto a las representaciones anatómicas los relevamientos en Cullen y El Páramo indican una mejor 
representación de los miembros en comparación con el esqueleto axial, situación análoga a la registrada en los conjuntos procedentes de bahía Thetis. En general los conjuntos de Cullen y El Páramo están menos meteorizados que el de bahía Thetis y a su vez muestran una mayor dispersión de valores. En este aspecto las mayores similitudes pueden hallarse entre los conjuntos de El Páramo y Bahía Thetis. El primero presenta estadios más leves, exhibiendo mayores frecuencias en los estadios 2 y 3 , pero a su vez con menor dispersión que los procedentes de Cullen. Tales similitudes resultan de interés dado el carácter natural de la depositación de los conjuntos de Cullen y El Páramo. Particularmente en el caso de este último se propone que el conjunto estaría conformado por el aporte de carcasas de O. flavescens muertos simultáneamente, probablemente un evento puntual en el tiempo (Borella \& Muñoz, 2006, p. 402). Si bien la dispersión de valores evidenciada en bahía Thetis no podría ser interpretada como producto de un único evento de carácter catastrófico, fue mencionado que el lapso de actividad de la factoría fue de aproximadamente una década, lo que en términos tafonómicos se diferencia de una situación de acumulación atricional a lo largo de un periodo prolongado.

Con la excepción de los orificios registrados en los cráneos, que interpretamos como ocasionados por la modalidad de matanza (a través de un golpe con un pico), no pudimos determinar otras marcas antrópicas en la muestra analizada. Esto señala una diferencia con las marcas de procesamiento determinadas en los conjuntos analizados por Muñoz (2000) y Cartajena y Labarca (2007), procedentes de sitios históricos de la isla Livingston en el archipiélago de las Shetland del Sur. Es posible que esta diferencia se deba, en parte, a distintas modalidades de procesamiento, aunque consideramos más acertado pensar que también podría ser atribuida a los avanzados estadios de meteorización registrados en el conjunto de bahía Thetis que pueden eliminar o enmascarar marcas previas (Fig. 9).

Los resultados presentados en este trabajo también permiten señalar que las actividades de explotación se focalizaron en apostaderos de Otaria flavescens, dado que se encuentran representados todos los grupos etarios para ambos sexos. Las frecuencias anatómicas observadas y los avanzados estadios de meteorización sugieren que el conjunto ha estado expuesto a procesos de destrucción posdepositacionales. Los perfiles de meteorización dominados por altos porcentajes de estadios 4 y 5 son poco frecuentes e indican un lapso de exposición sub-aérea de múltiples años con nula o poca sedimentación. Estos procesos, sumados al transporte diferencial de ciertas partes anatómicas, podrían haber tenido importancia en la conformación del perfil anatómico y los parámetros poblacionales registrados en el conjunto. Sobre la base de los perfiles etarios y dada la presencia de individuos de menos de un año, debemos concluir que las explotaciones eran realizadas sobre colonias reproductivas, hipótesis avalada también por la información histórica sobre el funcionamiento de la factoría. No obstante, es llamativa la baja proporción de cachorros en el conjunto de hemimandíbulas y fémures. A partir de la información tafonómica (perfiles de meteorización y frecuencias anatómicas) podemos inferir la existencia de un sesgo mediado por la preservación (y/o obstrusividad) diferencial de especímenes de distintas edades; es posible que las categorías de animales más pequeños estén sub-representadas, porque se han conservado o transportado más especímenes de animales de mayor tamaño, más densos y pesados. Esta situación implicaría un sesgo hacia un conjunto con una alta representación de machos adultos y subadultos grandes, lo que se verifica en los análisis realizados sobre el conjunto. Sin embargo, también debemos tener en cuenta que los animales que eran ultimados y faenados en la factoría eran arreados en pie desde loberías cercanas y que éstos no necesariamente representan el perfil poblacional de las colonias explotadas. A su vez, la matanza de muchos individuos era realizada en cercanías de las propias colonias y los productos obtenidos, en especial los cueros, eran transportados en fardos hasta la factoría (Carrara, 1952). Es lógico suponer que el arreo en pie era más adecuado para animales adultos y de mayor tamaño, lo que minimizaría los costos de transporte de los subproductos obtenidos. Por el contrario, la expectativa es que los animales más pequeños, sobre todo cachorros, no fueran aptos para recorrer todo el camino por la vía terrestre y que a su vez el transporte de los 
cueros de estas presas fuese menos costoso en términos de tiempo y esfuerzo. Por lo tanto, si los perfiles etarios y sexuales del conjunto óseo representado en el sitio no se ajustan claramente a las proporciones de categorías de edad y sexo esperadas para una colonia, podrían estar reflejando una pauta vinculada a los modos de explotación de las diferentes categorías de presas.

En sintesis, los resultados obtenidos sugieren el carácter secundario de estas acumulaciones de huesos, las cuales habrían sido conformadas por el transporte ocasionado por las mareas de los restos descartados en la bahía, producto de la faena de lobos marinos realizada en la factoría. Mantenemos la hipótesis más probable que el descarte de las carcasas completas o semi-completas se realizara en distintos sectores de la bahía y que la propia dinámica de las mareas haya acumulado los huesos en la costa, concentrando la mayor densidad de materiales y principalmente los más pesados en el lugar de máxima energía durante las pleamares y tormentas y los ítems más livianos hacia el interior. Asimismo, y sobre todo teniendo en cuenta que los restos de tejido muscular y los propios huesos no eran procesados para la obtención de aceite, debemos considerar la posibilidad de que muchas de las carcasas, o bien segmentos de éstas aun conservando buena parte de sus tejidos blandos, flotaran durante un tiempo posterior al descarte; esto facilitaría aún más su transporte por las mareas.

Hasta el momento hay escasas evidencias de concentraciones masivas de huesos de mamíferos marinos en Sudamérica. Un conjunto con una gran acumulación de restos de pinnípedos es el "Sitio Lobos" que describen Serrán y colaboradores (2008) en el golfo Nuevo -Península Valdés-. Pero este contexto presenta características depositacionales totalmente distintas al sitio que hemos analizado. Aunque se halló una gran densidad de restos de pinnípedos, los mismos se presentan en muchos casos articulados y los autores concluyen que una colonia de Otaria flavescens habría muerto masivamente, probablemente a causa de alguna enfermedad y luego fue sepultada rápidamente por un proceso de remoción en masa. En este contexto, deseamos destacar la singularidad de este tipo de depósitos, de carácter monoespecífico y compuestos por huesos de pinnípedos, lo que implica una característica inusual para este tipo de conjuntos de restos de vertebrados, que usualmente han sido descriptos para ungulados (por ejemplo: Miotti et al. 1999; Gutiérrez, 2001; Santiago \& Salemme, 2010, 2016).

\section{AGRADECIMIENTOS}

Los trabajos de campo fueron realizados en el marco del Programa Arqueológico Costa Atlántica (PACA) y el PICT 2013 1011. Agradecemos a Apache Energía Argentina S.R.L. y Total Austral S.A. por el financiamiento del PACA y a la Secretaría de Cultura de Tierra del Fuego y al Museo del Fin del Mundo por el respaldo institucional del PACA. También queremos agradecer a Jonathan W. Nye por su participación en la segunda campaña, a Alejandro Montes, Jimena Oria y María Paz Martinoli por sus aportes en diversos momentos de la redacción de este artículo y muy especialmente queremos expresar nuestro agradecimiento a Adolfo Imbert del Centro Hípico del Fin del Mundo por su inestimable colaboración en el traslado a bahía Thetis, así como en diversos aspectos de la organización y la estadía en el campo. Por último, agradecemos las sugerencias y aportes de dos evaluadores anónimos.

\section{BIBLIOGRAFÍA}

Aslan, A., \& Behrensmeyer, A. K. (1996). Taphonomy and time resolution of bone assemblages in a contemporary fluvial system: The East Fork River, Wyoming. Palaios, 411-421.

Baylis, A., Orben, R., Arnould, J. P. Y., Christiansen, F., Hays, G. C., \& Staniland, I. J. (2015). Disentangling the cause of a catastrophic population decline in a large marine mammal. Ecological Society of America, 96(10), 2834-2847.

Behrensmeyer, A. K. (1978). Taphonomic and ecology information from bone weathering. Paleobiology, 4, 150-162.

Behrensmeyer, A.K. (1991). Terrestrial Vertebrate Accumulations, En P. A. Allison, D. E. G. Briggs (Eds.), Taphonomy: Releasing the data locked in the fossil record. New York: Plenum Press.

Behrensmeyer, A. K. (2007). Bonebeds through geologic time. En R. R. Rogers, D. A. Eberth \& A. R. Fiorillo (Eds.), Bonebeds: Genesis, analysis, and paleobiological significance (pp. 65-102). Chicago: University of 
Chicago Press.

Binford, L.R. (1981). Bones: Ancient Men and Modern Myths. New York: Academic Press.

Borella, F. (2004). Tafonomía Regional y Estudios Arqueofaunísticos de cetáceos en Tierra del Fuego y Patagonia Meridional, British Archaeological Report (BAR 1257). Oxford: Archaeopress.

Borella, F., \& Favier Dubois, C. M. (1994-95). Observaciones Tafonómicas en la Bahía San Sebastián, costa norte de Tierra del Fuego, Argentina. Palimpsesto. Revista de Arqueología, 4, 1-8.

Borella, F., \& Muñoz, A. S. (2006). Observaciones tafonómicas sobre restos de Pinnípedos en la costa norte de Tierra del Fuego (Argentina). Intersecciones en Antropología, 7, 399-403.

Borella, F., \& Borrero L.A. (2017). Naturalistic Observations on the disarticulation of false killer whales (Pseudorca crassidens) Carcasses: fifteen years after, Journal of Taphonomy, 15, 45-58.

Borella, F., Grandi, F., Vales, D. G., Goodall, N., \& Crespo E. A. (2013). Esquema preliminar de fusión epifisaria en huesos de lobos marinos (Arctocephalus australis y Otaria flavescens), su contribución en los análisis zooarqueológicos. En F. Zangrando, R. Barberena, A. Gil, G. Neme, M. Giardina, L. Luna, C. Otaola, S. Paulides, L. Salgán \& A. M. Tivoli (Eds.), Tendencias teórico-metodológicas y casos de estudio en la arqueología de Patagonia (pp. 39-51). Buenos Aires: Museo de Historia Natural de San Rafael.

Borella, F., Gutiérrez, M. A., Foderé, H. R., \& Merlo, J. F. (2007). Estudio de densidad mineral ósea para dos especies de otáridos frecuentes en el registro arqueofaunístico patagónico (Otaria flavescens y Arctocephalus australis). En F. Morello, M. Martinic, A. Prieto \& G. Bahamonde (Eds.). Desenterrando Huesos, recolectando piedras, develando arcanos... VI Jornadas de Arqueología de Patagonia. (pp. 421426). Punta Arenas. Ediciones CEQUA.

Borrero, L. A. (1985). La Economía Prehistórica de los Habitantes del Norte de la Isla Grande de Tierra del Fuego. (Tesis Doctoral), Universidad de Buenos Aires. Argentina.

Borrero, L. A. (2004). Tafonomía de pinnípedos. En M. T. Civalero, P. Fernández \& G. Guraieb (Eds.), Contra viento y marea. Arqueología de la Patagonia (pp 445454). Buenos Aires: Instituto Nacional de Antropología y Pensamiento Latinoamericano.

Bruno Videla, P. (1980). Recursos naturales de Tierra del Fuego: Lobos marinos. Trabajo presentado en el $3 e r$
Congreso de Ciencias Históricas Fueguinas. Ushuaia.

Carrara, I. S. (1952). Lobos marinos, pingüinos y guaneras de las costas del litoral marítimo e islas adyacentes de la República Argentina. La Plata: Universidad Nacional de La Plata.

Cartajena, I., \& Labarca, R. (2007). Patrones históricos de cuereo en lobos marinos: la evidencia de los abrigos 1 y 2 de Playa Yámana (isla Livingston, Antártica chilena). Magallania, 35(1), 95-105.

Caviglia, S. E. (2012). Malvinas: Soberanía, Memoria y Justicia: 10 de junio de 1829. Rawson: Ministerio de Educación de la Provincia de Chubut.

Crespo, E. (1984). Dimorfismo sexual en los dientes caninos y en los cráneos de lobo marino del sur, Otaria flavescens (Shaw) (Pinnipedia, Otariidae). Revista del Museo Argentino de Ciencias Naturales (Bernardino Rivadavia) e Instituto Nacional de Investigación de las Ciencias Naturales, 13, 245-254.

Crespo, E. A. (1988). Dinámica poblacional del lobo marino del sur Otaria flavescens (Shaw, 1800) en el norte del litoral patagónico. Tesis de Doctorado en Ciencias Biológicas. Universidad Nacional de Buenos Aires, Buenos Aires, Argentina.

Eberth, D. A., Rogers, R. R., \& Fiorillo, A. R. (2007a). A Practical Approach to the Study of Bonebeds. En R. R. Rogers, D. A. Eberth, A. R. Fiorillo (Eds.), Bonebeds: Genesis, analysis, and paleobiological significance (pp. 265-331). Chicago: The University of Chicago Press.

Eberth, D. A., Shannon, M., \& Noland, B. G. (2007b). A Bonebeds Database: Classification, Biases, and Patterns of Occurrence En R. R. Rogers, D. A. Eberth, A. R. Fiorillo (Eds.), Bonebeds: Genesis, analysis, and paleobiological significance (pp. 103-131). Chicago: The University of Chicago Press.

Fisher, J. W. (1995). Bone surface modifications in zooarchaeology. Journal of Archaeological Method and Theory, 2(1), 7-68.

Frison, F. C., \& Todd, L. C. (1987). The Horner Site. The Type Site of the Cody Cultural Complex, Elsevier Inc. Orlando: Academic Press.

Gutiérrez, M. A. (2001). Bone Diagenesis and Taphonomic History of the Paso Otero 1 Bone Bed, Pampas of Argentina, Journal of Archaeological Science, 28, 1277-1290.

Lanata, J. L. (1995). Paisajes arqueológicos y propiedades del registro en el sudeste fueguino. Tesis Doctoral inédita. Facultad de Filosofía y Letras, Universidad de Buenos Aires. 
Lanata, J. L. (1996). The Haush puzzle: piecing together subsistence and settlement at the fueguian southeast. Revista do Museu de Arqueologia e Etnologia, 6, 11-32.

Lanata, J. L., \& Winograd, A. (1988). Gritos y susurros: aborígenes y lobos marinos en el litoral de la Tierra del Fuego, Arqueología de las Américas. $45^{\circ}$ Congreso Internacional de Americanistas, Fondo de Promoción de la Cultura, Bogotá.

Liebig, P. M., Taylor, T. S. A., \& Flessa, K. W. (2003). Bones on the beach: marine mammal taphonomy of the Colorado Delta, Mexico. Palaios, 18(2), 168-175.

Lyman, R. L. (1994). Vertebrate Taphonomy. Cambridge: Cambridge University Press.

Martinoli, M. P. (2017). Pautas de procesamiento y consumo de pinnípedos en la costa sur de Tierra del Fuego e Isla de los Estados: un análisis comparativo, Arqueología, 23, 173-196.

Martinoli, M. P., \& Vázquez, M. (2017). Pinniped Capture and Processing: A Comparative Analysis from Beagle Channel (Tierra del Fuego, Argentina). En M. Mondini, A. S. Muñoz, P. M. Fernández (Eds.), Zooarchaeology in the Neotropics Environmental diversity and human-animal interactions (pp. 7-23). Cham: Springer International Publishing.

Mengoni Goñalons, G. (1999). Cazadores de Guanacos de la Estepa Patagónica. Buenos Aires: Sociedad Argentina de Antropología.

Miotti, L., Vázquez, M., \& Hermo, D. (1999). Piedra Museo, un Yamnagoo Pleistocénico en la colonización de la Meseta de Santa Cruz. El estudio de la Arqueofauna. En INALP (Eds.), Soplando en el Viento (pp. 113-136). Bariloche: Universidad del Comahue.

Muñoz, A. S. (2000). Arqueofaunas de la isla Livingston, Shetland del Sur. Un estudio exploratorio de los restos de mamíferos recuperados en la península Byers. Archaeofauna, 9, 39-57.

Muñoz, A. S. (2002). La explotación de Mamíferos por cazadores-recolectores terrestres de Tierra del Fuego. (Tesis Doctoral), Universidad de Buenos Aires. Argentina.

Muñoz, A. S. (2011). Pinniped zooarchaeological studies in southern Patagonia: Current issues and future research agenda. En N. F. Bicho, J. Haws \& L. Davis (Eds.). Trekking the shore: Changing Coastlines and the Antiquity of Coastal Settlement. New York: Springer.

Nye, J. W., Zangrando, A. F., Martinoli, M. P., Vázquez, M. M., \& Fogel, M. (2018). Cumulative Human Impacts on Pinnipeds Over the Last 7,500 Years in Southern South America. SAA Archaeological Record, 18(4),
47-52.

Orquera, L. A., \& Piana, E. L. (1999). Arqueología de la región del canal Beagle (Tierra del Fuego, República Argentina). Buenos Aires: Sociedad Argentina de Antropología.

Piana, E. (2006). Antes y después. Marco de referencia del Viaje de James Weddell 1822-1824. Un viaje al polo sur: realizado en los años 1822-1824. Buenos Aires: Eudeba.

Quiroz, D. (2007). La caza de lobos marinos en isla Mocha. En D. Quiroz (Ed.), Etnografías mínimas. Santiago: Colección Etnografías del Siglo XXI.

Reeves, R. R. (2002). The origins and character of 'aboriginal subsistence' whaling: a global review. Mammal Review, 32(2), 71-106.

Rogers, R. R., \& Kidwell, S. M. (2007). A Conceptual Framework for the Genesis and Analysis of Vertebrate Skeletal Concentrations. En R. R. Rogers, D. A. Eberth \& A. R. Fiorillo (Eds.), Bonebeds: Genesis, analysis, and paleobiological significance, (pp. 1-63). Chicago: The University of Chicago Press.

Rogers, R. R., Eberth, D. A., \& Fiorillo, A. R. (2007). Bonebeds: genesis, analysis, and paleobiological significance. Chicago and London: The University of Chicago Press.

Santiago, F. C. (2013). La ocupación humana del norte de Tierra del Fuego durante el Holoceno medio y tardio: su vinculación con el paisaje. Ushuaia: Editora Cultural Tierra del Fuego.

Santiago, F. C., \& Salemme, M. C. (2010). A guanaco kill site in Tierra del Fuego, Argentina. Before Farming, 2(2), $1-17$

Santiago, F. C., \& Salemme, M. C. (2016). Guanaco hunting strategies in the northern plains of Tierra del Fuego, Argentina. Journal of Anthropological Archaeology, 43, 110-127.

Schiavini, A. (1993). Los lobos marinos como recurso para cazadores-recolectores marinos: El caso de Tierra del Fuego. Latin American Antiquity, 4, 346-366.

Schiavini, A., \& Raya Rey, A. (2001). Aves y mamíferos marinos en Tierra del Fuego: estado de situación, interacción con actividades humanas y recomendaciones para su manejo. Puerto Madryn: Fundación Patagonia Natural.

Senatore, M. X., Zarankin, A., Salerno, M. A., Valladares, I. V., \& Cruz, M. J. (2008). Historias bajo cero. Arqueología de las primeras ocupaciones humanas en Antártida. En L. Borrero \& V. Franco (Eds.), Arqueología del extremo sur del continente americano. Resultados de nuevos proyectos (pp. 148-171). Buenos Aires: Ed. Dunken. 
Serrán, M., Centeno, N., Weiler, N., \& Gómez Otero, J. (2008). Massive death of pinnipeds 1200 years ago: taphonomic history of the "Lobos site" (Golfo Nuevo, Patagonia, Argentina). Quaternary International, 183(1), 135-142.

Stehberg, R., \& Cabeza, A. (1987). Comienzos de la arqueología histórica antártica en el sitio Cuatro Pircas. Revista Chilena de Antropología, 6, 83-111.

Vairo, C. P. (2014). Segundo relevamiento de naufragios en la Península Mitre Tierra del Fuego, 1989. Bahía Thetis. Península Mitre. Factoría de Lobos Marinos. http:// www.histarmar.com.ar/SubArch/CARLOSPVAIRO/ Vairo-ExpPMitre/expedicionesVairo-BahiaTethisLoberia.htm (acceso: 15 de febrero de 2017).

Vázquez, M. (2015). Guanacos en el segundo componente de Túnel I (Canal Beagle). Un enfoque tafonómico. Magallania, 43, 251-277.

Vázquez, M. (2017). El "Lejano Oriente": prospecciones arqueológicas en la costa norte de Península Mitre. En M. Vázquez, D. Elkin \& J. Oría (Eds.), Patrimonio a orillas del mar: Arqueología del litoral Atlántico de Tierra del Fuego. Ushuaia: Editora Cultural Tierra del Fuego y Museo del Fin del Mundo.

Vázquez, M., \& Santiago, F. (2014). Explotación industrial de Pinnípedos en la factoría de bahía Thetis (Tierra del Fuego, Argentina): Una aproximación zooarqueológica. Revista Chilena de Antropología, 29, 130-135.

Vázquez, M., Álvarez, M., Barberena, R., Borrazzo, K., Borrero, L. A., Elkin, D., Grosso..., \& Santiago, F. (2010). Programa arqueológico costa atlántica: hacia la preservación del patrimonio arqueológico costero en Tierra del Fuego. En R. Bárcena \& H. Chiavazza (Eds.), Arqueología en el Bicentenario de la Revolución de Mayo. XVII Congreso Nacional de Arqueología Argentina, (Tomo II, pp. 557562). Mendoza: Universidad Nacional de Cuyo.

Vázquez, M., Borrero, L. A., Elkin, D., Grosso, M., Murray, C., Oría, J., Salemme, M., \& Santiago, F. (2013). Nuevos resultados sobre la localización de sitios en la costa atlántica fueguina: Programa Arqueológico Costa Atlántica (PACA). En A. F. Zangrando, R. Barberena,
A. Gil, G. Neme, M. Giargina, L. Luna, C. Otaola, S. Paulides, L. Salgán \& A. Tivoli (Comps.), Tendencias Teórico-metodológicas y casos de estudio en la arqueología de la Patagonia, (pp. 609-616). Mendoza: Museo de Historia Natural de San Rafael.

Voorhies, M. R. (1969). Taphonomy and population dynamics of an early Pliocene vertebrate fauna, Knox County, Nebraska (Vol. 1). Laramie: University of Wyoming.

Winograd, A. (1984). Presencia de pinnípedos en el litoral septentrional. Informe PEOAF 1984 (pp. 70-101), Museo Territorial, Ushuaia. Manuscrito.

Winograd, A. (2008). Patagonia. Mitos y certezas. Buenos Aires: Edhasa.

Zangrando, A. F. (2009). Historia evolutiva y subsistencia de cazadores-recolectores marítimos de Tierra del Fuego. Buenos Aires: Sociedad Argentina de Antropología.

Zangrando, A. F., Orquera, L. A., \& Piana, E. (2010). Diversificación e intensificación de recursos animales en la secuencia arqueológica del canal Beagle (Tierra del Fuego, Argentina). En M. A. Gutiérrez, M. De Nigris, P. M. Fernández, M. Giardina, A. Gil, A. Izeta, G. Neme, H. Yacobaccio, H. (Eds.), Zooarqueología a principios del Siglo XXI: Aspectos teóricos, metodológicos y casos de estudio (pp. 359-370) Buenos Aires: Ediciones del Espinillo.

Zangrando, A. F., Panarello, H., \& Piana, E. L. (2014). Zooarchaeological and stable isotopic assessments on pinniped-human relations in the Beagle Channel (Tierra del Fuego, southern South America). International Journal of Osteoarchaeology, 24(2), 231-244.

Zanola, O. P. (2002). Capítulo 8, Valor Cultural. En Península Mitre. Proyecto de creación de un área protegida en el extremo sudoriental de la Isla Grande de Tierra del Fuego, Rep. Argentina. Ministerio de Economía, Obras y Servicios Públicos. Secretaría de Planeamiento y Desarrollo. Ushuaia.

Zarankin, A., \& Senatore, M. X. (2007). Historias de un Pasado en Blanco: Arqueología Histórica Antártica. Belo Horizonte: Argumentvm. 